\title{
New species and records of Lobrathium Mulsant \& Rey (Coleoptera, Staphylinidae, Paederinae) from China
}

\author{
Wen-Rong Li ${ }^{1, \dagger}$, Mei-Jun Zhao ${ }^{1, \neq}$, Cong-Chao Dai ${ }^{1, \S}$ Li-Zhen Li ${ }^{1,1}$ \\ I Department of Biology, College of Life and Environmental Sciences, Shanghai Normal University, Shanghai, \\ 200234, P. R. China \\ † urn:lsid:zoobank.org:author:670C3BA4-C6D9-4E20-BA8D-1D44001BEB39 \\ ¥ urn:lsid:zoobank.org:author:FBE4FA1F-5BCF-405E-98C1-4F86894643EA \\ § urn:lsid:zoobank.org:author:F296F7D8-8259-4A69-841C-C2F74F0A54E7 \\ | urn:lsid:zoobank.org:author:BBACC7AE-9B70-4536-ABBE-54183D2ABD45
}

Corresponding author: Li-Zhen Li (lizhenli@shnu.edu.cn)

Academic editor: J. Klimaszewski | Received 25 April 2013 | Accepted 23 May 2013 | Published 27 May 2013

urn:lsid:zoobank.org:pub:28AOB3CF-755C-4503-8F04-2C85663D9B29

Citation: Li W-R, Zhao M-J, Dai C-C, Li L-Z (2013) New species and records of Lobrathium Mulsant \& Rey (Coleoptera, Staphylinidae, Paederinae) from China. ZooKeys 304: 49-81. doi: 10.3897/zookeys.304.5406

\begin{abstract}
Seven new species of the genus Lobrathium Mulsant \& Rey from China are described and illustrated: L. anatinum $\mathrm{Li} \& \mathrm{Li}$, sp. n. (Guangxi), L. diaoluoense $\mathrm{Li} \& \mathrm{Li}$, sp. n. (Hainan), L. dufui $\mathrm{Li} \& \mathrm{Li}$, sp. n. (Hubei), L. lirunyui Li \& Li, sp. n. (Guizhou), L. pengi Li \& Li, sp. n. (Guangxi), L. quyuani Li \& Li, sp. n. (Hubei) and L. uncinatum Li \& Li, sp. n. (Qinghai). A recent key to the species of mainland China is modified to accommodate the new species. New locality data are provided for eleven species.
\end{abstract}

\section{Keywords}

Coleoptera, Staphylinidae, Paederinae, Lobrathium, China, taxonomy, new species

\section{Introduction}

According to a recent revision (Assing 2012), the genus Lobrathium Mulsant \& Rey, 1878 is represented in China by 43 species (24 species from mainland China and 20 from Taiwan, with Lobrathium hongkongense distributed both in mainland China and Taiwan). Later, Li et al. (2013) described four additional species from mainland China:

Copyright Wen-Rong Li et al. This is an open access article distributed under the terms of the Creative Commons Attribution License 3.0 (CC-BY), which permits unrestricted use, distribution, and reproduction in any medium, provided the original author and source are credited. 
L. quadrum (Li, Solodovnikov \& Zhou 2013), L. rutilum (Li, Solodovnikov \& Zhou 2013), L. tortuosum (Li, Solodovnikov \& Zhou 2013) and L. zonalis (Li, Solodovnikov $\&$ Zhou 2013). Herein, we report seven new species of Lobrathium from mainland China and additional locality data for eleven species.

\section{Material and methods}

All the material treated in this study is deposited in the Insect Collection of Shanghai Normal University, Shanghai, China (SNUC).

Type labels are cited in their original spelling. A slash (/) is used to separate different labels. Type material bears the following type label: 'HOLOTYPE [red] or PARATYPE [yellow], [genus name, species name], sp. n., [authors of the species], det. 2013.

The specimens were killed with ethyl acetate and then dried. Materials were stored in $75 \%$ ethanol; genitalia and small parts were embedded in Euparal on plastic slides that were attached to the same pin with the specimens.

Morphological studies were carried out using an Olympus SZX 16 stereoscope. A digital camera Canon EOS 50D with MP-E $65 \mathrm{~mm}$ Macro Photo Lens was used for the habitus photos. An Olympus CX21 microscope and a digital camera Canon G9 were used for the photos of small structures. The map was created using MapGis.

The measurements of various body parts are abbreviated as follows: BL-length of the body from the labral anterior margin to the anal end; HL-length of the head from the anterior margin of the frons to the posterior margin of the head; HW-maximum width of the head; PL-length of the pronotum along the midline; PW-maximum width of the pronotum; EL-length of the elytra from the anterior margin to the elytral posterior margin along suture; $\mathbf{E W}$-maximum width of the elytra; $\mathbf{A L}-$ length of the aedeagus from the apex of the ventral process to the base of the aedeagal capsule.

\section{Taxonomy}

Key to the Lobrathium species of mainland China (modified from Assing 2012: 84-86)

$1 \quad$ Elytra with posterior portion partly or completely yellowish or reddish, mostly with yellowish spots, and often with bluish to purple hue ........................2

- $\quad$ Elytra uniformly dark-brown to blackish .............................................. 15a

2 Elytra with more or less extensive yellowish coloration posteriorly, at least posterior two fifths completely yellowish ................................................ 2a

- $\quad$ Elytra less extensively yellowish or reddish posteriorly, usually with more or less defined spots often leaving the lateral and/or posterior margins blackish........ 4

2a $\quad$ : sternite VI with modified, stout and short black setae (Fig. 18D). Qinghai 
- $\quad \delta$ : sternite VI without modified, stout and short black setae.

2b $\widehat{o}$ : sternite VII with modified, stout and short black setae (Fig. 8D). Hubei. L. dufui Li \& Li sp. n.

$\hat{O}^{\lambda}$ : sternite VII without modified, stout and short black setae ... 3

$\widehat{\jmath}$ : posterior excision of sternite VIII smaller and less deep; aedeagus $1.1 \mathrm{~mm}$ long, with ventral process apically undivided. Shaanxi: Qinling Shan

L. schuelkei Assing, 2012

$\sigma^{\lambda}$ : posterior excision of sternite VIII slightly larger and somewhat deeper; aedeagus larger, $1.2-1.3 \mathrm{~mm}$ long, ventral process apically with two long processes. Hubei, Beijing, Shanxi....

L. taureum Assing, 2012 Large species; length of forebody at least $4.9 \mathrm{~mm}$. Pronotum broad, 1.101.20 times as long as broad. Elytra 0.90-0.95 times as long as pronotum and without bluish hue. $\widehat{\jmath}$ : sternite VII with distinctly modified, short and stout black setae; sternite VIII with conspicuously deep posterior excision, its depth at least approximately half the length of sternite; ventral process of aedeagus ventrally with rasp-like structures.... Smaller species; length of fore body $4.6 \mathrm{~mm}$ at most. Pronotum more slender, 1.20-1.35 times as long as broad, only in one species broader (L. radens). Elytra often longer than pronotum and often with bluish or purple hue. $\delta$ : sternite VII in most species without strongly modified setae; sternite VIII with less deep posterior excision, except in L. bispinosum and L. tuberosum.........5a Pronotum slightly broader, 1.10-1.15 times as long as broad. $\hat{\jmath}$ : posterior excision of sternite VIII extremely deep, reaching well beyond middle of sternite; aedeagus $1.6 \mathrm{~mm}$ long, ventral process with two rasp-like projections and stoutly blade-shaped. Northern Yunnan: Diancang Shan....

L. excisissimum Assing, 2012

Pronotum slightly less broad, 1.15-1.20 times as long as broad. §̊: posterior excision of sternite VIII less deep, approximately reaching middle of sternite; aedeagus $1.5 \mathrm{~mm}$ long, ventral process with more numerous rasp like projections, somewhat more slender and apically more acute in ventral view. Eastern Guizhou: Leigong Shan

L. radens Assing, 2012 $\widehat{~}{ }^{\prime}$ : aedeagus $1.70-1.72 \mathrm{~mm}$ long, ventral process apically not bifid (Fig. 2C). Guangxi L. anatinum Li \& Li sp. $\mathrm{n}$.

$\widehat{~}{ }^{\prime}$ : aedeagus $1.35 \mathrm{~mm}$ long, ventral process apically bifid

6 Elytral spots situated in anterior portion of posterior half of elytra (i.e., at some distance from posterior margin). Dorsal surface of head uneven, with median and lateral impressions. Punctation of head and pronotum extremely dense. Relatively large species; length of fore body 4.4-4.6 mm. Antennae

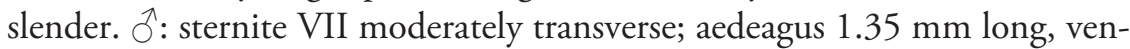
tral process apically bifid. Western Hubei: Daba Shan, Guizhou, Shaanxi ....

L. ablectum Assing, 2012

- Elytral spots situated at or near posterior margin of elytra. Dorsal surface of head without distinct impressions. Punctation of head and pronotum less 
dense. Smaller species, length of fore body usually $4.0 \mathrm{~mm}$ at most, except for L. spathulatum $(3.7-4.5 \mathrm{~mm})$. Male sexual characters different. A reliable identification of the following species is possible only based on the male sexual characters.

$\delta$ : bifurcation of the apex of the ventral process of the aedeagus forming an angle of more than 30 degrees in lateral view (Fig. 12B). Guangxi, Shiwanda Shan

$\sigma^{\lambda}$ : bifurcation of the apex of the ventral process of the aedeagus forming an angle of less than 30 degrees in lateral view (Fig. 7B). Hainan

L. diaoluoense Li \& Li sp. n.

Elytra black, without bluish or purple hue, 0.9-1.0 times as long as pronotum.

Elytra usually with, rarely without bluish or purple hue, 1.0-1.15 times as long as pronotum.

$\delta^{\lambda}$ : sternite VIII with small posterior excision in asymmetric position, posterior margin with tooth-like projection on either side of excision; aedeagus approximately $1.5 \mathrm{~mm}$ long, ventral process very long, slender, and apically asymmetric. Widespread: Sichuan, Shaanxi, Hubei, Guizhou....L. tortile Zheng, 1988 $\sigma^{3}$ : sternite VIII with deep posterior excision in symmetric position; aedeagus of different morphology.....

$\delta^{\lambda}$ : aedeagus $0.9-1.0 \mathrm{~mm}$ long, ventral process long, slender, apically acute, and very thin at base; sternite VIII with very broad and deep posterior excision, on either side of excision with dense pubescence. Central Sichuan: Qingcheng Shan L. gladiatum Zheng, 1988 Male sexual characters different

10 : sternite VII anteriorly with tubercle; sternite VIII oblong and with Ushaped posterior excision; aedeagus $1.2 \mathrm{~mm}$ long and with massive ventral process. Jiangxi

L. tuberosum Assing, 2012 $\delta$ : sternite VII without tubercle; posterior excision of sternite VIII of different shape; aedeagus longer, at least approximately $1.4 \mathrm{~mm}$ long

11 : sternite VII with shallow posterior impression with pubescence; sternite VIII with moderately deep posterior excision and of characteristic chaetotaxy; aedeagus $1.4 \mathrm{~mm}$ long and with ventral process of distinctive shape. Northeastern Hubei, Zhejiang.

L. demptum Assing, 2012

- $\quad \widehat{O}$ : sternite VII with more pronounced posterior impression without pubescence; posterior excision of sternite VIII much deeper, broader, and of subtrapezoid shape; aedeagus longer, $1.5 \mathrm{~mm}$ long, ventral process with two tooth-like projections ventrally. Southeastern Guizhou, Jiangxi .

\section{L. bispinosum Assing, 2012}

12 Elytra with weak purple hue; posterior spots relatively small, defined, and of circular shape. Pronotum less oblong, approximately 1.2 times as long as broad. $\hat{\delta}$ : sternite VII moderately transverse and with moderately deep pos- 
terior excision; aedeagus $1.0 \mathrm{~mm}$ long, ventral process with dorsal carina and apically acute. Northern Yunnan ............... L. retrocarinatum Assing, 2012

- $\quad$ Elytra usually with bluish hue; posterior spots usually larger and/or of different shape or less defined. Pronotum more oblong, at least approximately 1.25 times as

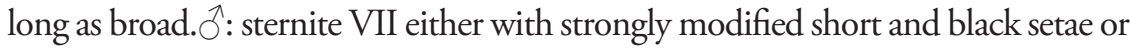
without modified setae at all; sternite VIII and aedeagus of different shape ....... 13

13 : sternite VII with distinctly modified short and stout black setae; sternite VIII with deep U-shaped posterior excision; aedeagus approximately $1.2 \mathrm{~mm}$ long, ventral process of distinctive morphology. Sichuan, Shaanxi, Yunnan..

L. bebeatum Zheng, 1988

- $\quad \quad \quad \quad \quad$ : sternite VII without distinctly modified setae; sternite VIII with less deep and differently shaped posterior excision; aedeagus of different morphology ........ 14

$14 \widehat{\jmath}$ : posterior excision of sternite VII small; aedeagus approximately $1.0 \mathrm{~mm}$ long. Widespread and common species: China, Taiwan, southern Japan ......

\section{L. hongkongense Bernhauer, 1931}

$\quad \quad \quad \quad \quad \quad \quad$ : posterior excision of sternite VII larger and of broadly triangular shape; aedeagus of different shape. Species with more restricted distributions.... 14a

$14 \mathrm{a} \widehat{\jmath}$ : aedeagus ventral process broader, evenly narrowed and acute apically in ventral view (Fig. 13C). Hubei

L. quyuani Li \& Li sp. n.

- $\quad \delta$ : aedeagus ventral process of different shape in ventral view ..................15

$15 \hat{0}$ : aedeagus of somewhat variable shape and size, $1.3-1.5 \mathrm{~mm}$ long, ventral process very slender, apically acute, and weakly asymmetric; sternites VII and VIII as in Figs 4D, E. Widespread in China: Shaanxi, Sichuan, Hubei, Yunnan, Qinghai

L. configens Assing, 2012

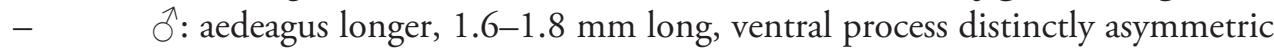
and apically distinctly dilated (ventral view); sternites VII and VIII as in Figs 14D, E. Widespread in China: Sichuan, Shaanxi, Shanxi, Hubei, Zhejiang..

L. spatbulatum Assing, 2012

15a Body reddish to reddish-brown; head posterior angles not marked, punctation fine and dense; eyes very small, one third as long as distance from posterior margin of eyes to neck; elytra 1.25 times as wide as pronotum. 0 : aedeagus $1.56 \mathrm{~mm}$ long, ventral process of distinctive morphology (Figs 11A-E). Guizhou L. lirunyui $\mathrm{Li} \& \mathrm{Li}$ sp. n.

- $\quad$ Male characters different 16

\section{Lobrathium ablectum Assing}

http://species-id.net/wiki/Lobrathium_ablectum

Figs 1

Lobrathium ablectum Assing, 2012: 106. Type locality: creek valley 8 km NW Muyuping, Daba Shan, Hubei. 


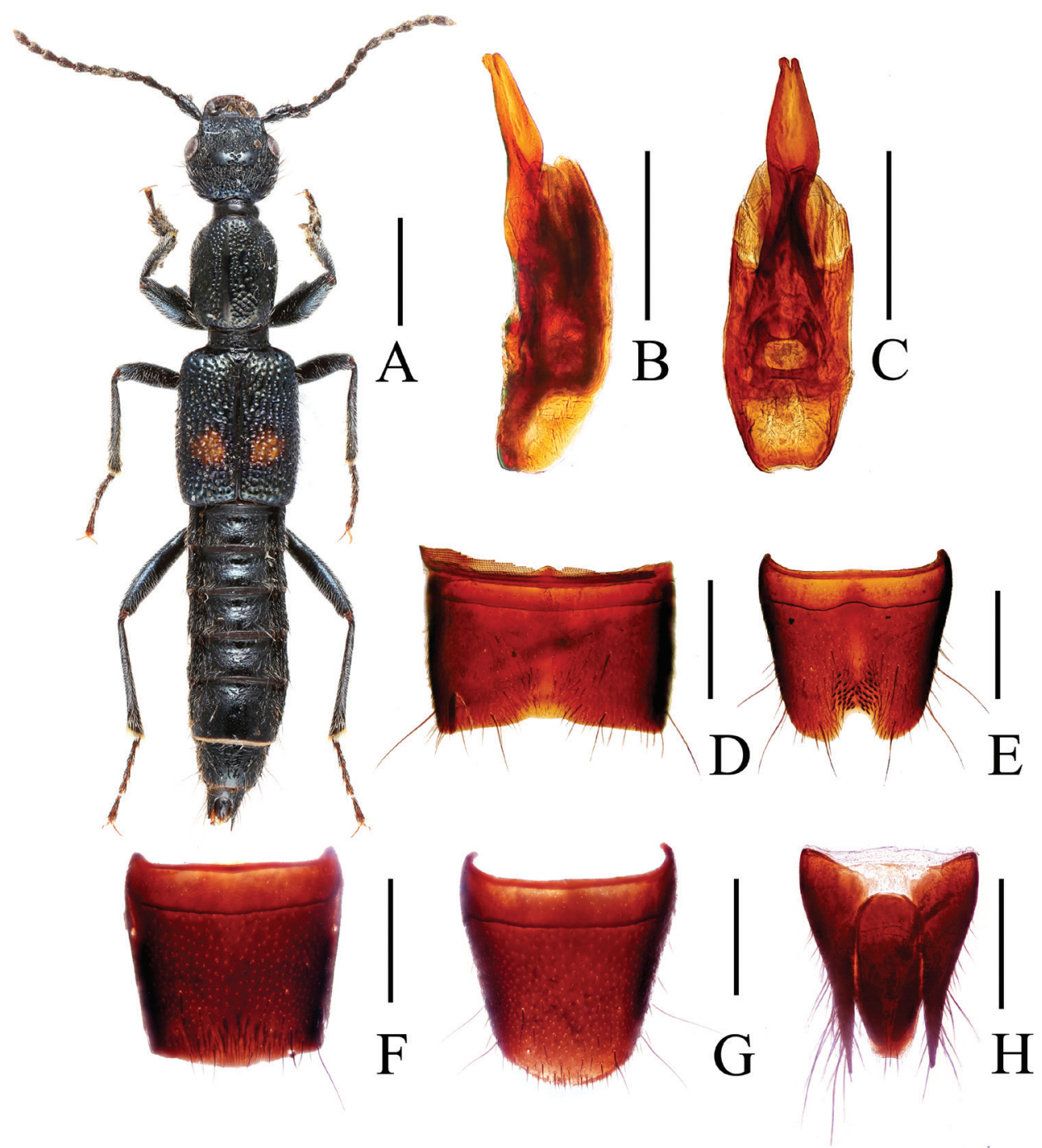

Figure I. Lobrathium ablectum. A habitus $\mathbf{B}$ aedeagus in lateral view $\mathbf{C}$ aedeagus in ventral view $\mathbf{D}$ male sternite VII E male sternite VIII $\mathbf{F}$ female tergite VIII $\mathbf{G}$ female sternite VIII $\mathbf{H}$ female tergites IX-X. Scales: A $1 \mathrm{~mm}, \mathbf{B}-\mathbf{H} 0.5 \mathrm{~mm}$.

Material examined ( $6 \hat{\partial} \hat{\partial}, 1$ ) $)$. China, Shaanxi: $3 \hat{\partial} \widehat{\partial}, 1$, , Hanzhong City, Nanzheng County, Yuanba Town, Liping National F. P., 3250'N, 106 $36^{\prime} \mathrm{E}, 1400-1600$

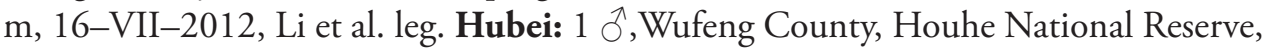

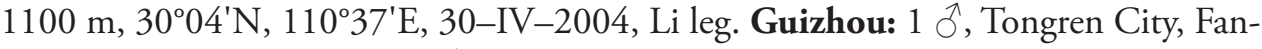
jing Shan, Hu \& Tang leg.; 1 $\widehat{\text { }}$, Yanhe County, Wanjia Village, Mayanghe N. R., 900 $\mathrm{m}, 28^{\circ} 51^{\prime} \mathrm{N}, 108^{\circ} 21^{\prime} \mathrm{E}, 03-\mathrm{X}-2007$, Zhu leg.

Distribution. The known distribution is confined to the Daba Shan (Assing 2012) and the Wuling Shan in Hubei, Guizhou, and Shaanxi. 


\section{Lobrathium anatinum $\mathrm{Li} \& \mathrm{Li}$, sp. $\mathrm{n}$.}

urn:lsid:zoobank.org:act:9D9DA5B9-5138-437B-B2B9-81E536FD2E6E

http://species-id.net/wiki/Lobrathium_anatinum

Figs 2

Type material $(2 \lesssim \widehat{\jmath})$. Holotype, $\widehat{\jmath}$ : "China, Guangxi, Lingui County, Anjiangping, $1700 \mathrm{~m}, 25^{\circ} 33^{\prime} \mathrm{N}, 109^{\circ} 55^{\prime} \mathrm{E}, 17-\mathrm{VII}-2011$, Peng Zhong leg. / Holotype ${ }^{\wedge}$, Lobrathium anatinum, sp. n. Li \& Li, det. 2013". Paratype, ỡ: "China, Guangxi, Lingui County, Anjiangping, 1400-1700 m, 253' N, 109'56'E, 14-VII-2011, Peng Zhong

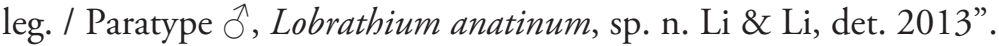

Description. Body length 7.28-7.89 mm, length of fore body $3.89-4.0 \mathrm{~mm}$. Habitus as in Fig. 2A. Coloration: body black with distinct bluish hue, middle of elytra with yellowish spot not reaching lateral and posterior margins; legs blackish with paler tarsi, antennae dark brownish to blackish.

Head weakly transverse $(\mathrm{HW} / \mathrm{HL}=1.10-1.11)$, widest across eyes; posterior angles broadly rounded; punctation dense and moderately coarse, sparser in median dorsal portion; interstices without microsculpture. Eyes large, more than half as long as distance from posterior margin of eye to neck in dorsal view. Antenna long and slender, 1.96-2.22 mm long.

Pronotum 1.24-1.30 times as long as broad, as wide as head $(\mathrm{PW} / \mathrm{HW}=1.0)$, lateral margins convex in dorsal view, punctation similar to that of head, but with impunctate midline, interstices glossy.

Elytra wider than pronotum and nearly as long as pronotum $(\mathrm{EL} / \mathrm{EW}=0.95-1.0$, $\mathrm{EW} / \mathrm{PW}=1.15-1.3, \mathrm{EL} / \mathrm{PL}=0.91-0.94)$; punctation coarse and dense, arranged in series; interstices without microsculpture. Hind wings apparently present.

Abdomen broader than elytra; punctation fine and dense; posterior margin of tergite VII with palisade fringe.

Male. Sternite VII (Fig. 2D) strongly transverse and with distinct median impression, this impression without pubescence, posterior margin broadly concave; sternite VIII (Fig. 2E) weakly transverse, with long and pronounced postero-median impression, this impression with numerous modified, stout and short black setae, posterior excision moderately broad and moderately deep, on either side of this excision with long dark setae; aedeagus (Figs 2B, C) 1.70-1.72 mm long, ventral process long, flattened, and apically convex in ventral view.

Female. Unknown

Etymology. The specific epithet (Latin, adjective: of a duck) refers to the shape of the ventral process of the aedeagus, which somewhat resembles the mouth of a duckbill.

Comparative notes. This species is close to L. ablectum Assing (2012) in sharing a similar shape and chaetotaxy of the sternites VII and VIII. The new species differs from L. ablectum by larger body size, and by the longer, apically not bifid ventral process of the aedeagus.

Habitat and distribution. The present species was sifted from wet moss near a cold stream (Fig. 20A) in the Angjiangping National Reserve, Guangxi (Fig. 19), in July. 


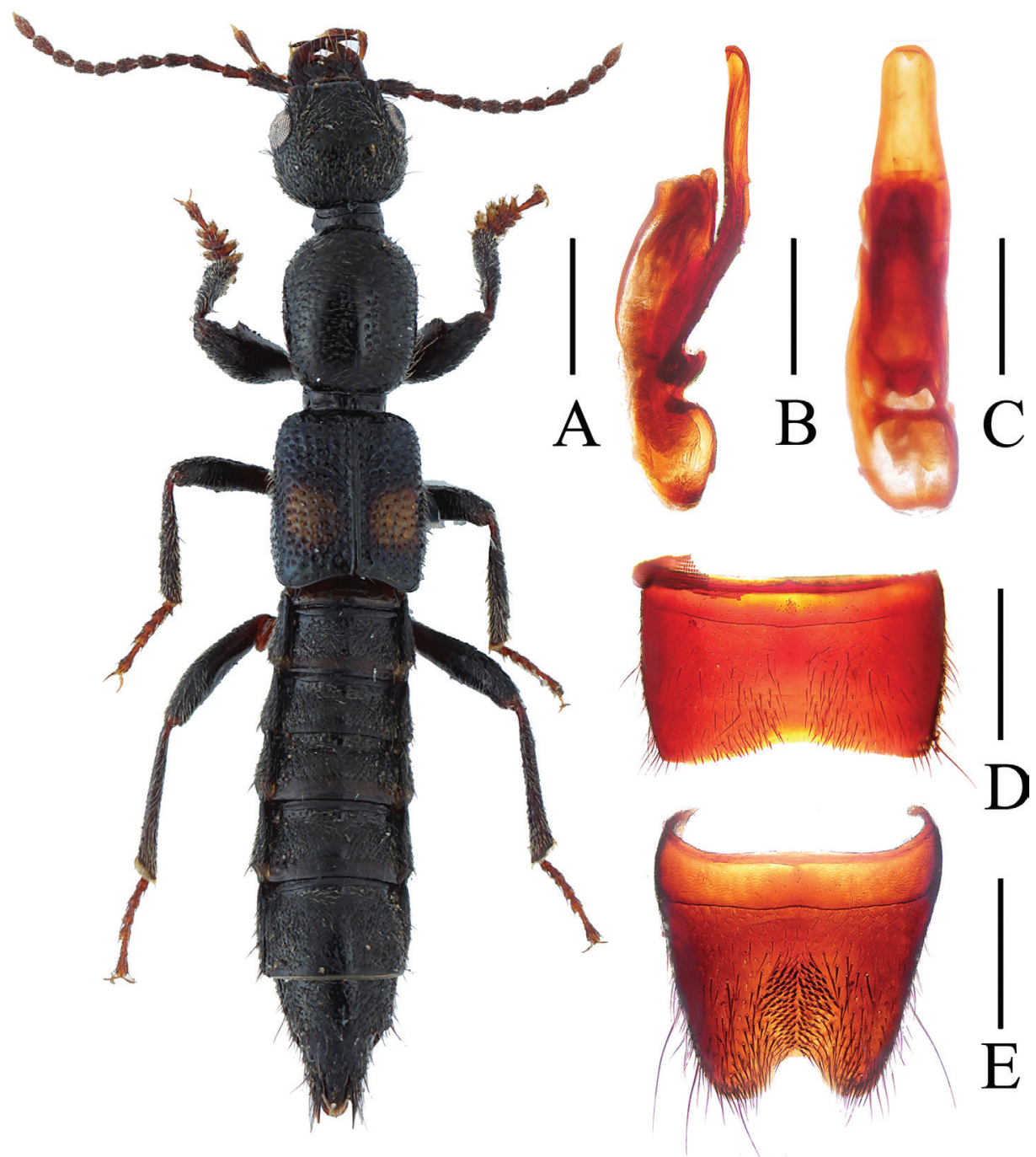

Figure 2. Lobrathium anatitum. A habitus $\mathbf{B}$ aedeagus in lateral view $\mathbf{C}$ aedeagus in ventral view $\mathbf{D}$ male sternite VII E male sternite VIII. Scales: A $1 \mathrm{~mm}$, B-E $0.5 \mathrm{~mm}$.

\section{Lobrathium bispinosum Assing}

http://species-id.net/wiki/Lobrathium_bispinosum Figs 3

Lobrathium bispinosum Assing, 2012: 97. Type locality: Leigong Shan, 15 km Leishan, Leishan County, Guizhou.

Material examined $(1 \AA)$. China, Jiangxi: $1 \curvearrowright$, Jinggangshan City, Ciping Town, $850 \mathrm{~m}, 26^{\circ} 29^{\prime} \mathrm{N}, 114^{\circ} 05^{\prime} \mathrm{E}, 18-\mathrm{X}-2010$, Peng et al. leg. 

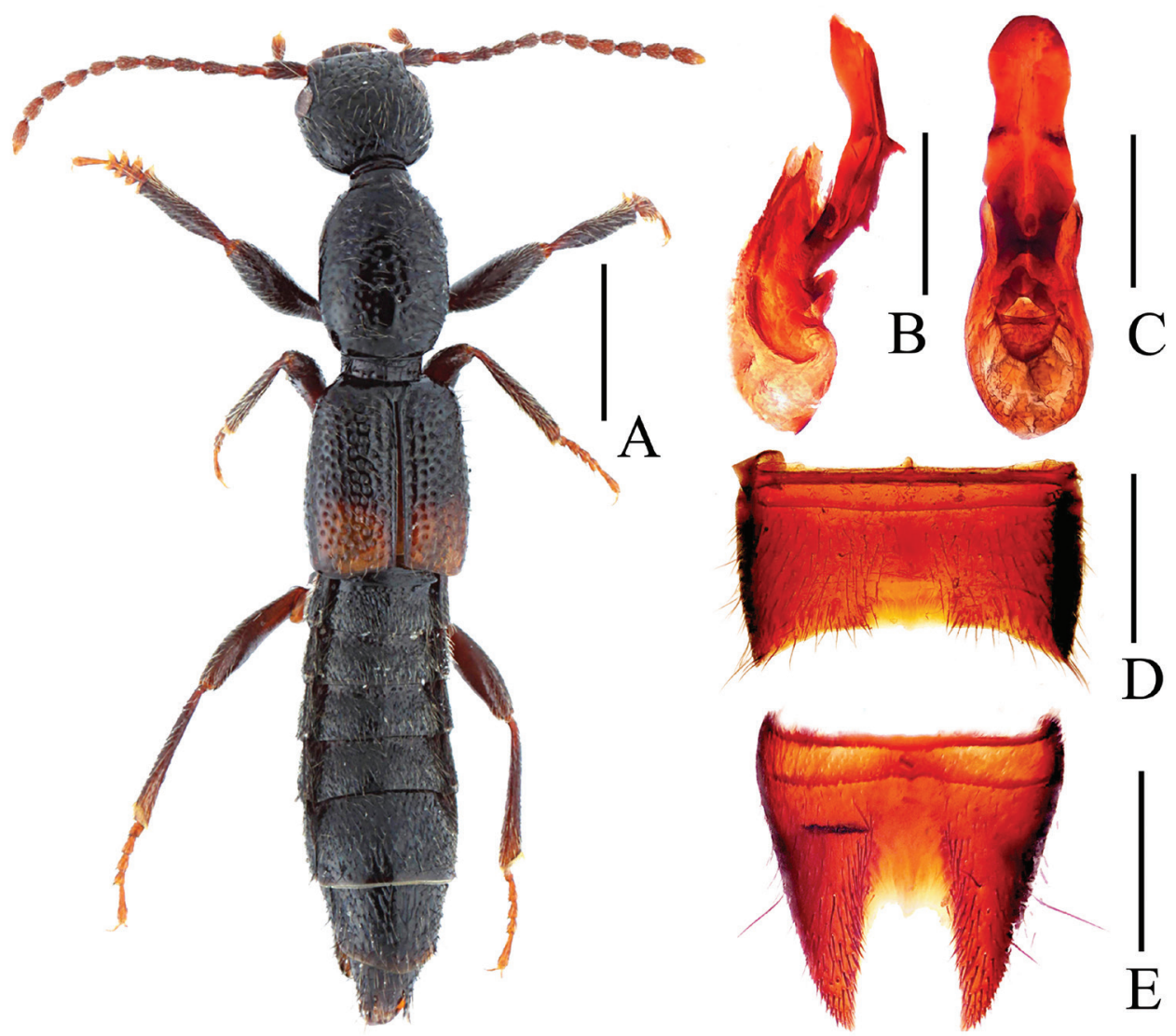

Figure 3. Lobrathium bisponsum. A habitus $\mathbf{B}$ aedeagus in lateral view $\mathbf{C}$ aedeagus in ventral view $\mathbf{D}$ male sternite VII E male sternite VIII. Scales: A $1 \mathrm{~mm}$, B-E $0.5 \mathrm{~mm}$.

Distribution. The original description of L. bispinosum is based on specimens from Guizhou (Assing 2012). The above record from Jiangxi extends the distributional range eastwards about 700 kilometers.

\section{Lobrathium configens Assing}

http://species-id.net/wiki/Lobrathium_configens

Figs 4

Lobrathium configens Assing, 2012: 93. Type locality: 115 km WSW Xi'an, river bank above Houzhenzi, Qinling Shan, Shaanxi.

Material examined $(2 \lesssim \widehat{\jmath})$. China, Yunnan: $1 \hat{\jmath}$, Hutiaoxia, Jinxing, $1800 \mathrm{~m}$, $27^{\circ} 11^{\prime} \mathrm{N}, 100^{\circ} 06^{\prime} \mathrm{E}, 22-\mathrm{IV}-2005$, Huang leg. Qinghai: $1{ }^{\lambda}$, Menda N. R., $2500 \mathrm{~m}$, $35^{\circ} 47^{\prime} \mathrm{N}, 107^{\circ} 48^{\prime} \mathrm{E}, 24-\mathrm{VII}-2004$, Hu et al. leg. 


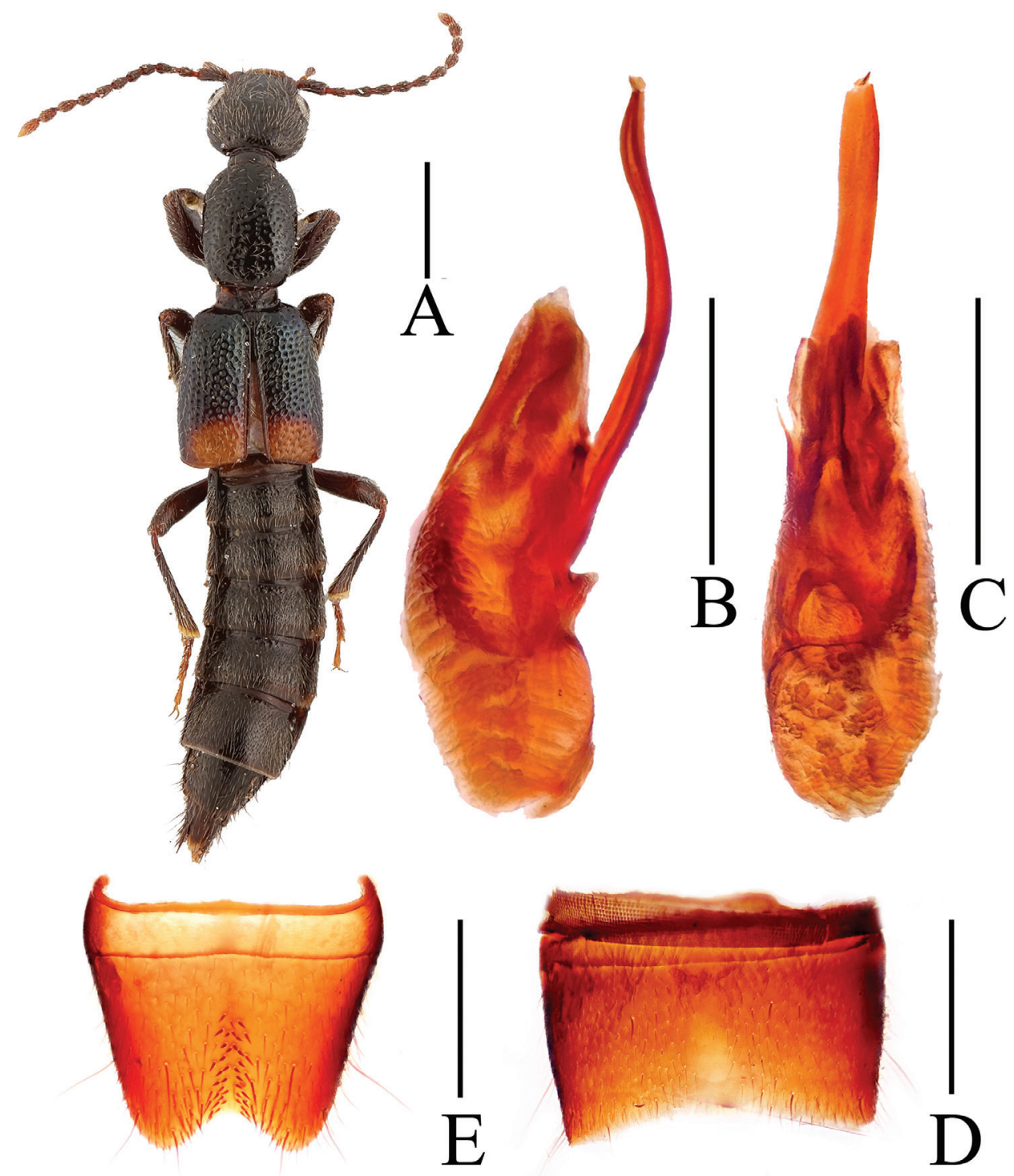

Figure 4. Lobrathium configens. $\mathbf{A}$ habitus $\mathbf{B}$ aedeagus in lateral view $\mathbf{C}$ aedeagus in ventral view $\mathbf{D}$ male sternite VII E male sternite VIII. Scales: A $1 \mathrm{~mm}$, B-E $0.5 \mathrm{~mm}$.

Distribution. The original description of $L$. configens is based on specimens from Hubei, Sichuan, Yunnan, and Shaanxi (Assing 2012). The above records extend the wide distributional range of $L$. configens southwards by about 1200 kilometers. 


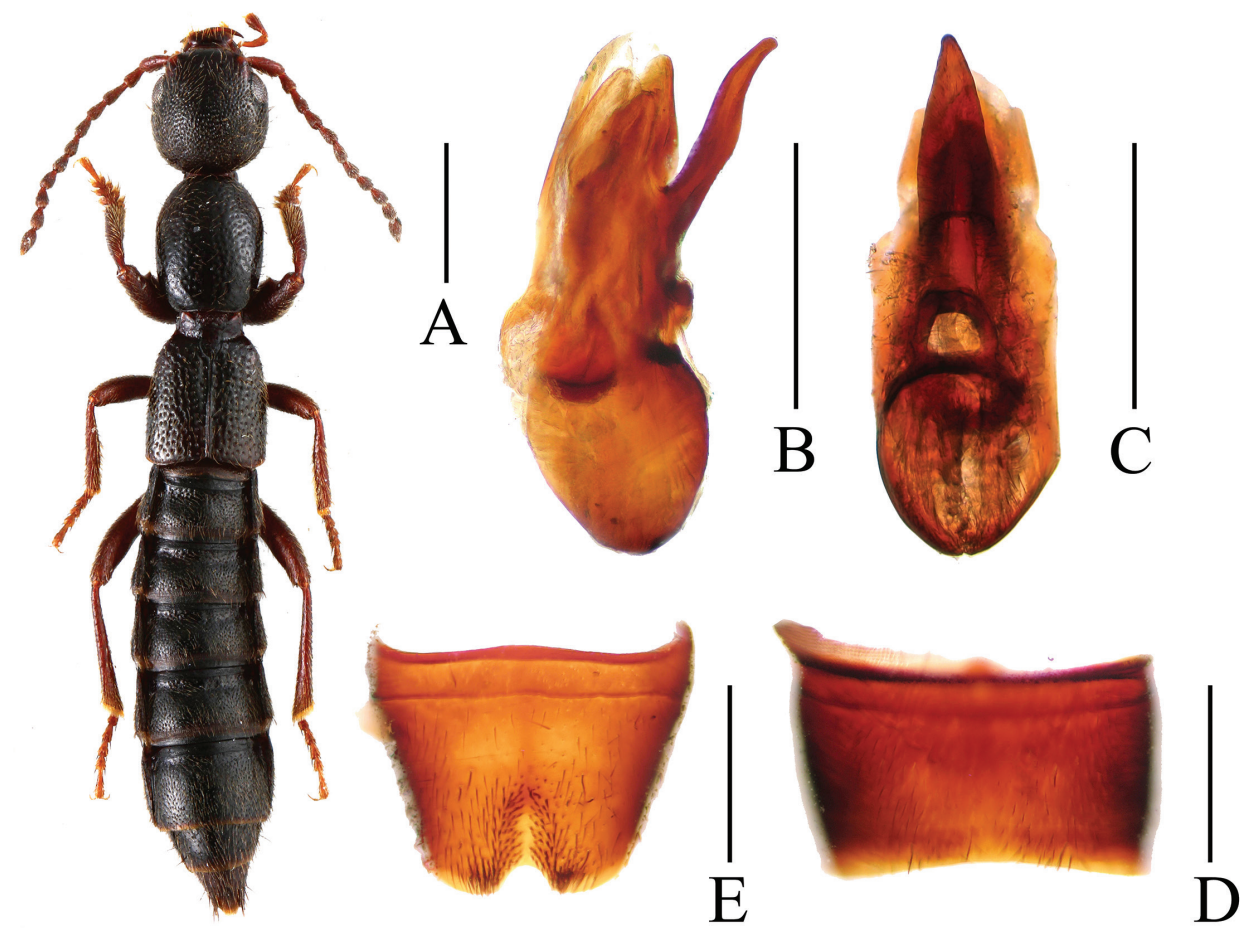

Figure 5. Lobrathium daxuense. A habitus $\mathbf{B}$ aedeagus in lateral view $\mathbf{C}$ aedeagus in ventral view $\mathbf{D}$ male sternite VII E male sternite VIII. Scales: A $1 \mathrm{~mm}$, B-E $0.5 \mathrm{~mm}$.

\section{Lobrathium daxuense Assing}

http://species-id.net/wiki/Lobrathium_daxuense Figs 5

Lobrathium daxuense Assing, 2012: 109. Type locality: Daxue Shan, Sichuan.

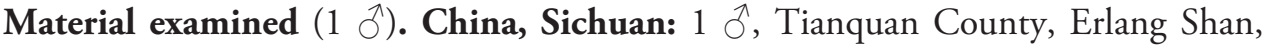
Yakou $3.6 \mathrm{~km}, 29^{\circ} 31^{\prime} \mathrm{N}, 102^{\circ} 17^{\prime} \mathrm{E}, 2600-2800 \mathrm{~m}, 11-\mathrm{VII}-2012$, Peng et al. leg.

Distribution. Sichuan.

\section{Lobrathium demptum Assing}

http://species-id.net/wiki/Lobrathium_demptum

Figs 6

Lobrathium demptum Assing, 2012: 97. Type locality: Dabie Shan, Hubei.

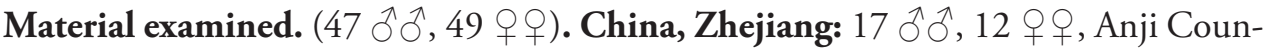

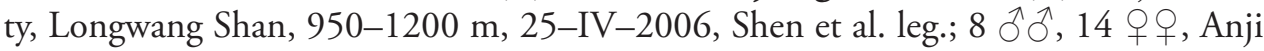




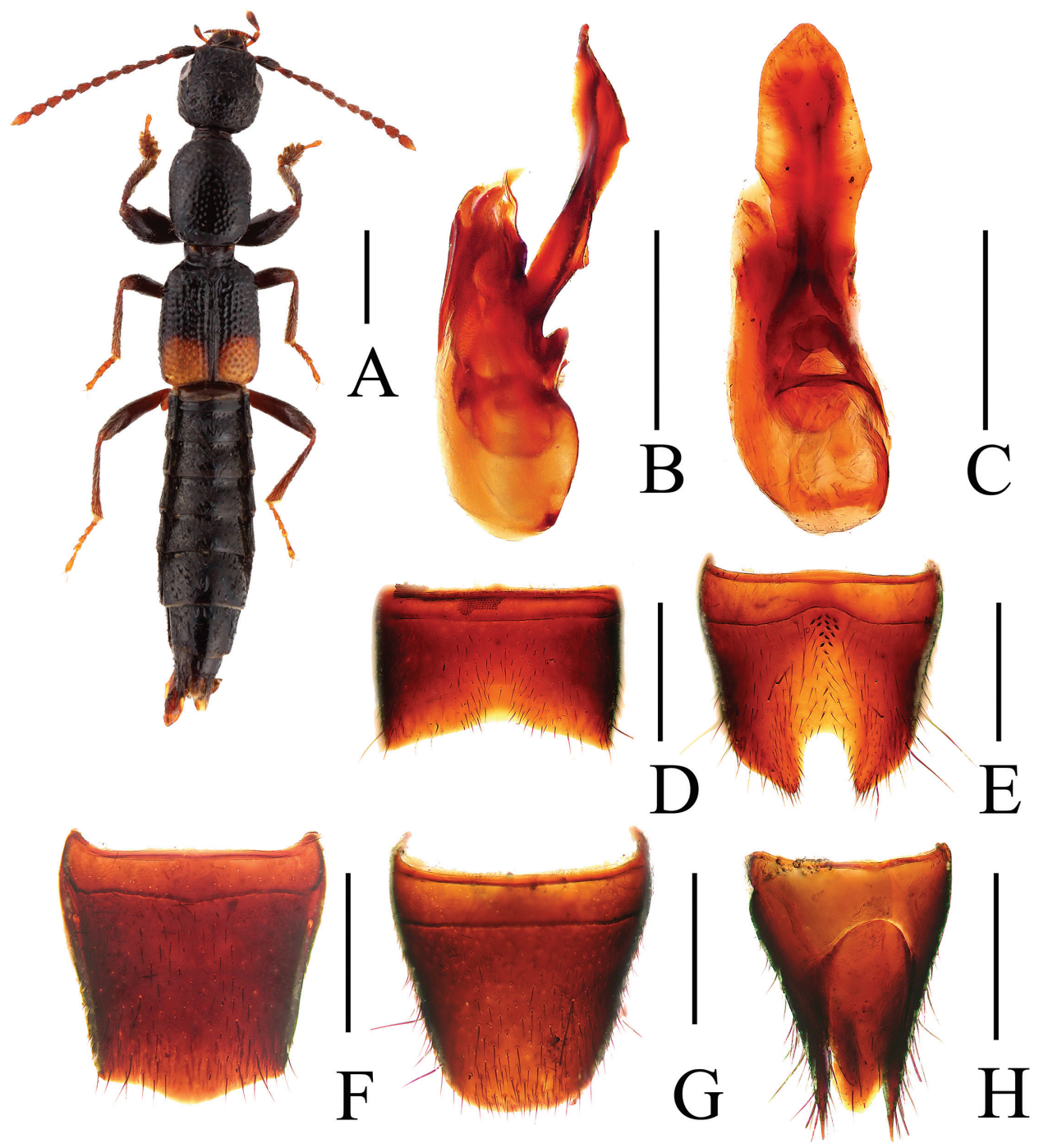

Figure 6. Lobrathium demptum. A habitus $\mathbf{B}$ aedeagus in lateral view $\mathbf{C}$ aedeagus in ventral view $\mathbf{D}$ male sternite VII E male sternite VIII $\mathbf{F}$ female tergite VIII $\mathbf{G}$ female sternite VIII $\mathbf{H}$ female tergites IX-X. Scales: A $1 \mathrm{~mm}, \mathbf{B}-\mathbf{H} 0.5 \mathrm{~mm}$.

County, Longwang Shan, 950-1200 m, 25-IV-2004, Tang et al. leg.; 2 ふ઼, 1 q, Anji County, Longwang Shan, 300-500 m, 23-IV-2004, Zhu leg.; 11 ふึે, 12 q ㅇ, Anji

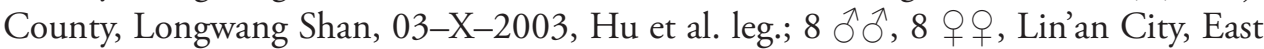
Tianmu Shan, 1050-1150 m, 13-IV-2011, Peng \& Zhu leg.; 1 ふै, 2 q Shan, Gaoling, 800 m, 26-IV-2008, He \& Tang leg.

Distribution. The original description of $L$. demptum is based on specimens from the Dabie Shan, Hubei (Assing 2012). The above records from Zhejiang extend the range towards the southeast by about 400 kilometers. 


\section{Lobrathium diaoluoense $\mathrm{Li} \& \mathrm{Li}$, sp. $\mathrm{n}$.}

urn:lsid:zoobank.org:act:712D3A23-CF9D-454E-864A-48C10F88F56B

http://species-id.net/wiki/Lobrathium_diaoluoense

Figs 7

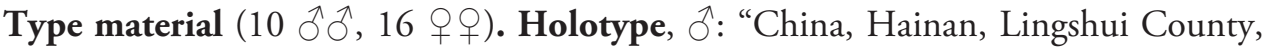
Diaoluo Shan, 1000 m, 18 $43^{\prime} \mathrm{N}, 109^{\circ} 51$ 'E, 24-IV-2012, Peng Zhong \& Dai Congchao leg. / Holotype $\sigma^{\lambda}$, Lobrathium diaoluoense, sp. n., Li \& Li, det. 2013". Paratypes, $9 \hat{\partial} \widehat{\partial}, 16$ 우: same data as holotype.

Description. Body length 4.61-5.95 mm, length of fore body $2.94-3.28 \mathrm{~mm}$. Habitus as in Fig. 7A. Coloration: body black, posterior portion of elytra with yellowish spot reaching posterior and lateral margins; legs with paler tarsi; antennae yellowish.

Head as long as broad or weakly oblong ( $\mathrm{HL} / \mathrm{HW}=1.0-1.09)$; posterior angles marked; punctation coarse and dense, sparser in median dorsal portion, interstices without microsculpture. Eyes large, more than half as long as distance from posterior margin of eye to neck. Antenna slender, 1.54-1.78 mm long.

Pronotum slender, approximately as wide as head (PL/PW $=1.25-1.31, \mathrm{PW} /$ $\mathrm{HW}=0.96-1.0)$, lateral margins weakly convex in dorsal view; punctation dense and coarse, similar to that of head, median dorsal portion more sparsely punctate or impunctate; interstices without microsculpture and glossy.

Elytra longer and broader than pronotum $(\mathrm{EL} / \mathrm{EW}=1.09-1.15$, EW/PW $=1.24-$ 1.37, EL/PL = 1.11-1.14); humeral angles marked; punctation coarse and dense, interstices without microsculpture and glossy. Hind wings fully developed.

Abdomen distinctly narrower than elytra; punctation fine and dense; posterior margin of tergite VII with palisade fringe; posterior margin of tergite VIII weakly concave, without appreciable sexual dimorphism.

Male. Sternite VII (Fig. 7D) with deep and broad median impression without pubescence, posterior margin broadly and rather strongly concave; sternite VIII oblong, with deep and large U-shaped posterior excision (Fig. 7F), without modified setae, on either side of posterior excision with long dark setae; aedeagus (Figs 7B, C) with ventral process of very distinctive morphology, furcate apically, and this bifurcation forming an angle of less than 30 degrees in lateral view.

Female. Posterior margin of tergite VIII (Fig. 7G) weakly convex; sternite VIII (Fig. 7H) of similar shape as tergite VIII; tergite IX (Fig. 7I) undivided anteriorly; tergite $\mathrm{X}$ of subovoid shape.

Etymology. The specific epithet (adjective) is derived from the Diaoluo Shan where the type locality is situated.

Comparative notes. This species is similar to L. bipeniculatum Assing (2010) and L. pengi Li \& Li sp. n. (described below) in sharing similar shapes of the male sternites VII and VIII, and of the aedeagus. It can be separated from L. bipeniculatum by the broader median impression of the male sternite VII (Fig. 7D), and by the absence of clusters of long dark setae at the margins of the posterior excision of the male sternite VIII (Fig. 7F). In L. pengi, the ventral process of the aedeagus is of different shape, with the apical bifurcation forming an angle of more than 30 degrees in lateral view. 


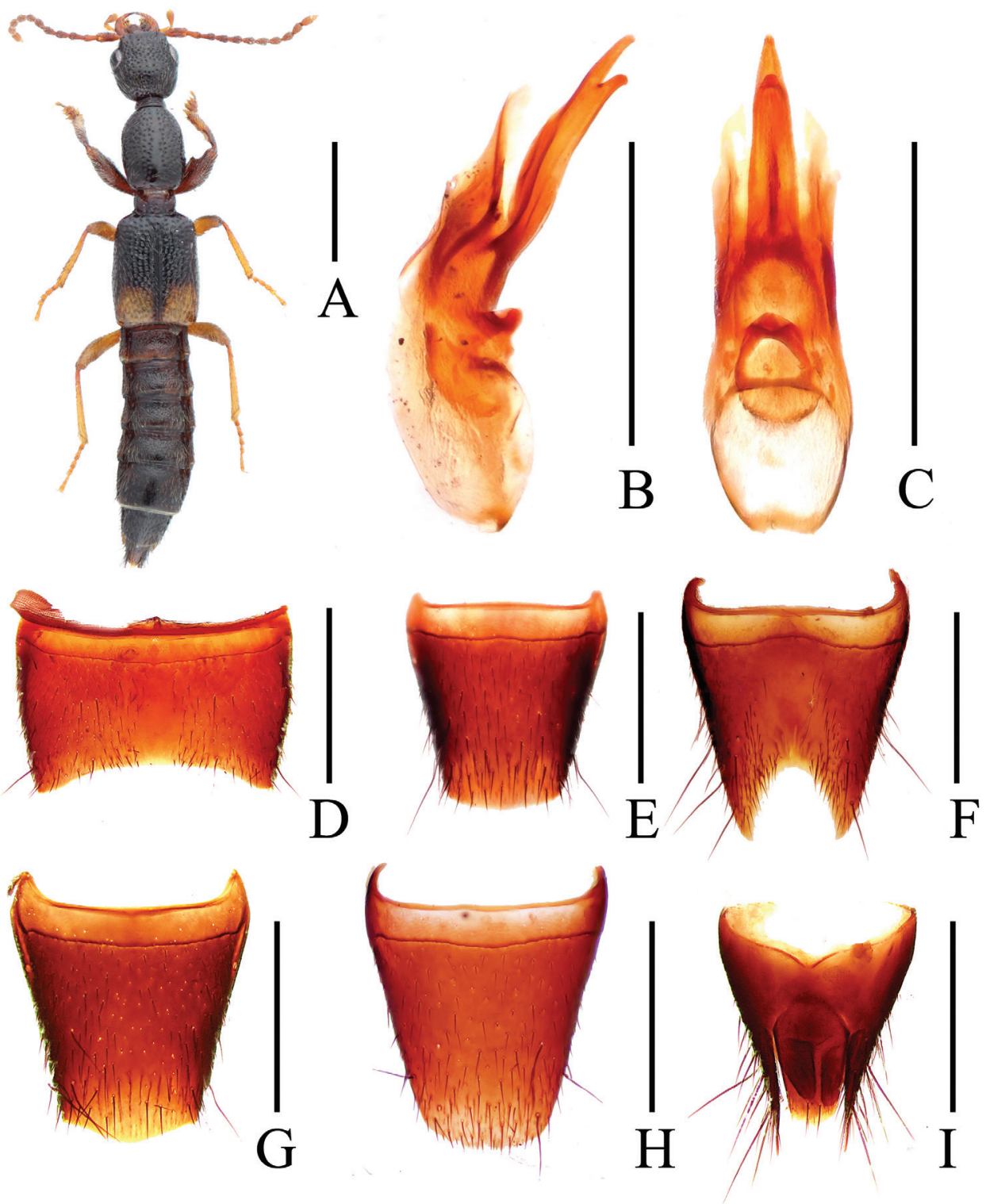

Figure 7. Lobrathium diaoluoense. A habitus B aedeagus in lateral view $\mathbf{C}$ aedeagus in ventral view D male sternite VII E male tergite VIII F male sternite VIII G female tergite VIII $\mathbf{H}$ female sternite VIII I female tergites IX-X. Scales: A $1 \mathrm{~mm}, \mathbf{B}-\mathbf{I} 0.5 \mathrm{~mm}$.

Habitat and distribution. The present species was sifted from wet moss on stones alongside a reservoir (red circle in Fig. 20B) in the Diaoluo Shan, Hainan (Fig. 19), in April. 


\section{Lobrathium dufui Li \& Li, sp.n.}

urn:Isid:zoobank.org:act:48A1D1FD-6CAB-4238-8190-6FBB06DAB5B5

http://species-id.net/wiki/Lobrathium_dufui

Figs 8

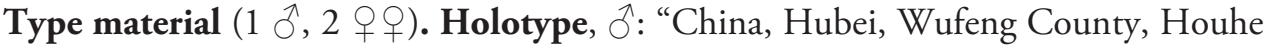
National Reserve, 30-IV-2004, 1100 m, 3004'N, 110³7'E, Li Li-zhen leg. / Holotype $\hat{O}$, Lobrathium dufui, sp. n. Li \& Li, det. 2013”. Paratypes, 2 우: same data as holotype.

Description. Body length 5.84-6.89 mm, length of fore body $3.34-3.61 \mathrm{~mm}$. Habitus as in Fig. 8A. Coloration: body black, posterior portion of elytra with oblong yellowish spot of at least $2 / 5$ the length of elytra and reaching posterior margins and lateral margins; legs blackish with slightly paler tibiae and tarsi; antennae brown.

Head weakly transverse $(\mathrm{HW} / \mathrm{HL}=1.02-1.09)$, widest at eyes, weakly tapering behind eyes; posterior angles rounded, not marked; punctation coarse and moderately dense, sparser in median dorsal portion and on frons; interstices without microsculpture. Eyes large, more than half the length of postocular region from posterior margin of eyes to neck in dorsal view. Antenna slender, $1.72-2.18 \mathrm{~mm}$ long.

Pronotum approximately as wide as head $(\mathrm{PL} / \mathrm{PW}=1.25-1.31$, PW/HW $=0.96-$ 1.10); lateral margins weakly convex in dorsal view; punctation dense and coarse, similar to that of head, but with impunctate midline; interstices without microsculpture and glossy.

Elytra broader than pronotum $(\mathrm{EL} / \mathrm{EW}=1.02-1.06, \mathrm{EW} / \mathrm{PW}=1.21-1.39, \mathrm{EL} /$ $\mathrm{PL}=1.01-1.08)$; humeral angles marked; punctation coarse and dense. Hind wings apparently present.

Abdomen distinctly narrower than elytra; punctation fine and dense; posterior margin of tergite VII with palisade fringe; tergite VIII (Fig. 8F) without appreciable sexual dimorphism, posterior margin broadly convex.

Male. sternite VII (Fig. 8D) transverse and posteriorly with pronounced impression of triangular shape, this impression impunctate in the middle and laterally with a few modified, stout and short black setae, posterior margin broadly and weakly concave; sternite VIII (Fig. 8E) weakly transverse, with deep and broad, U-shaped posterior excision, median impression furnished with numerous modified, stout, short and black setae; aedeagus (Figs 8B, C) with ventral process of very distinctive morphology, apically with fissure and bifid.

Female. Sternite VIII (Fig. 8G) weakly transverse, posteriorly convex; tergite IX (Fig. $8 \mathrm{H}$ ) undivided anteriorly, anterior margin emarginated in the middle; tergite $\mathrm{X}$ of subovoid shape.

Etymology. The species is named after the famous late poet $\mathrm{Fu} \mathrm{Du}$, who was born in Hubei.

Comparative notes. This species is similar to L. uncinatum Li \& Li sp. n. (described below) in external characters, and to L. hebeatum Zheng (1988) in sexual characters. It differs from L. uncinatum by the shape of the aedeagus and by the absence of 

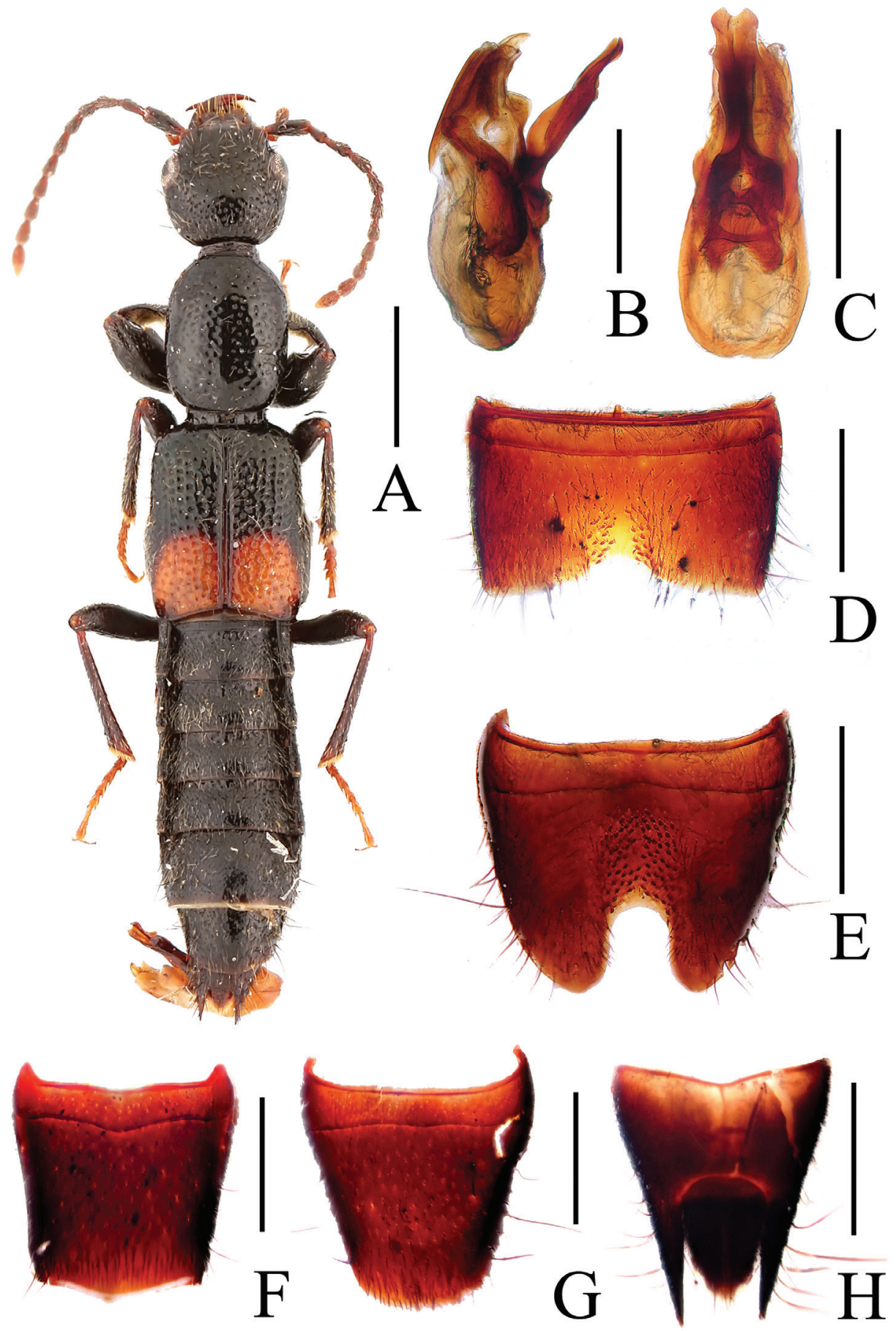

Figure 8. Lobrathium dufui. A habitus $\mathbf{B}$ aedeagus in lateral view $\mathbf{C}$ aedeagus in ventral view $\mathbf{D}$ male sternite VII E male sternite VIII F female tergite VIII G female sternite VIII $\mathbf{H}$ female tergites IX-X. Scales: A $1 \mathrm{~mm}, \mathbf{B}-\mathbf{H} 0.5 \mathrm{~mm}$. 
modified setae on the male sternite VI, and from L. hebeatum by the shape of the apex of the ventral process of the aedeagus.

Habitat and distribution. The type specimens were sifted from wet moss near a stream (Fig. 20C) in Hubei (Fig. 19).

\section{Lobrathium hebeatum Zheng}

http://species-id.net/wiki/Lobrathium_hebeatum

Figs 9

Lobrathium hebeatum Zheng, 1988: 189. Type locality: Emei Shan, Sichuan.

Lobrathium hebeatum Zheng: Assing, 2012: 91. New distribution: Sichuan, Shaanxi,

Yunnan.

Material examined ( $6 \hat{\sigma} \widehat{\sigma}, 8 q q)$. China, Shaanxi: $4 \hat{\sigma} \hat{\sigma}, 5 q q$, Foping N. R.,

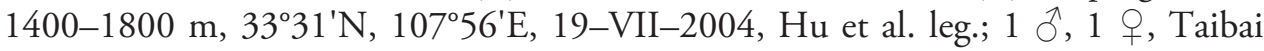
Shan, $1450-1750 \mathrm{~m}, 34^{\circ} 03^{\prime} \mathrm{N}, 107^{\circ} 53^{\prime} \mathrm{E}-33^{\circ} 53^{\prime} \mathrm{N}, 107^{\circ} 48^{\prime} \mathrm{E}, 15-\mathrm{VII}-2004, \mathrm{Hu}$ $\&$ Tang leg. Sichuan: 1 ก, 2 우, Luding County, Hailuogou, 3000 m, 2944'N, $102^{\circ} 07^{\prime} \mathrm{E}, 25-\mathrm{VII}-2006$, Hu \& Tang leg.

Distribution. Sichuan, Yunnan, Shaanxi.

\section{Lobrathium hongkongense Bernhauer}

http://species-id.net/wiki/Lobrathium_hongkongense

Figs 10

Lathrobium hongkongense Bernhauer1931: 127. Type locality: Hongkong.

Lobrathium sibynium Zheng, 1988: 186. Distribution: Sichuan; Assing, 2012: 86, proposed synonymy. New distribution: Jiangsu, Zhejiang, Hubei, Guangxi, Sichuan, Yunnnan.

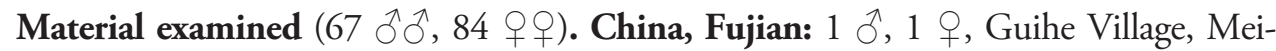
hua Shan, 1200 m, 2519'N, 116 51'E, 31-V-2007, Huang \& Xu leg. Guizhou: $1 \sigma^{\top}$, 1 q, Suiyang County, Kuankuoshui N. R., Baishaogou, 700 m, 28 10'N, 107²16'E, 04-VI-2010, Lu et al. leg. Yunnan: 3 ふึग, 1 q, Nabanhe N. R., Chuguohe, Bengganghani, 1750 m, 28-IV-2009, Hu \& Yin leg. Zhejiang: 1 đ̃, 2 o , Zhuji City, Dongbai

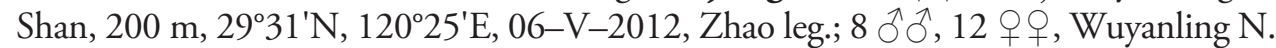
R., 700 m, 10-IV-2004, Hu et al. leg.; 7 ふふ, 13 q , Wenzhou City, Yandang Shan, 50-350 m, 29-V-2006, Li \& Shen leg.; 1 đ̃, 1 ․, Pan'an County, Dapan Shan, 550800 m, 06-VI-2006, Li \& Shen leg.; 25 ふ઼ふ, 22 우우, Baishanzu N.R., 1200-1360 m, 05-V-2004, Hu et al. leg.; 20 ふ઼ふ, 31 우, Gutian N. R., 5-7-V-2005, Zhu \& Li leg.

Comment. For illustrations of the female sexual characters see Figs 10G-H.

Distribution. Widespread species, recorded from Jiangsu, Zhejiang, Fujian, Hubei, Guangxi, Sichuan, Guizhou, and Yunnan. 


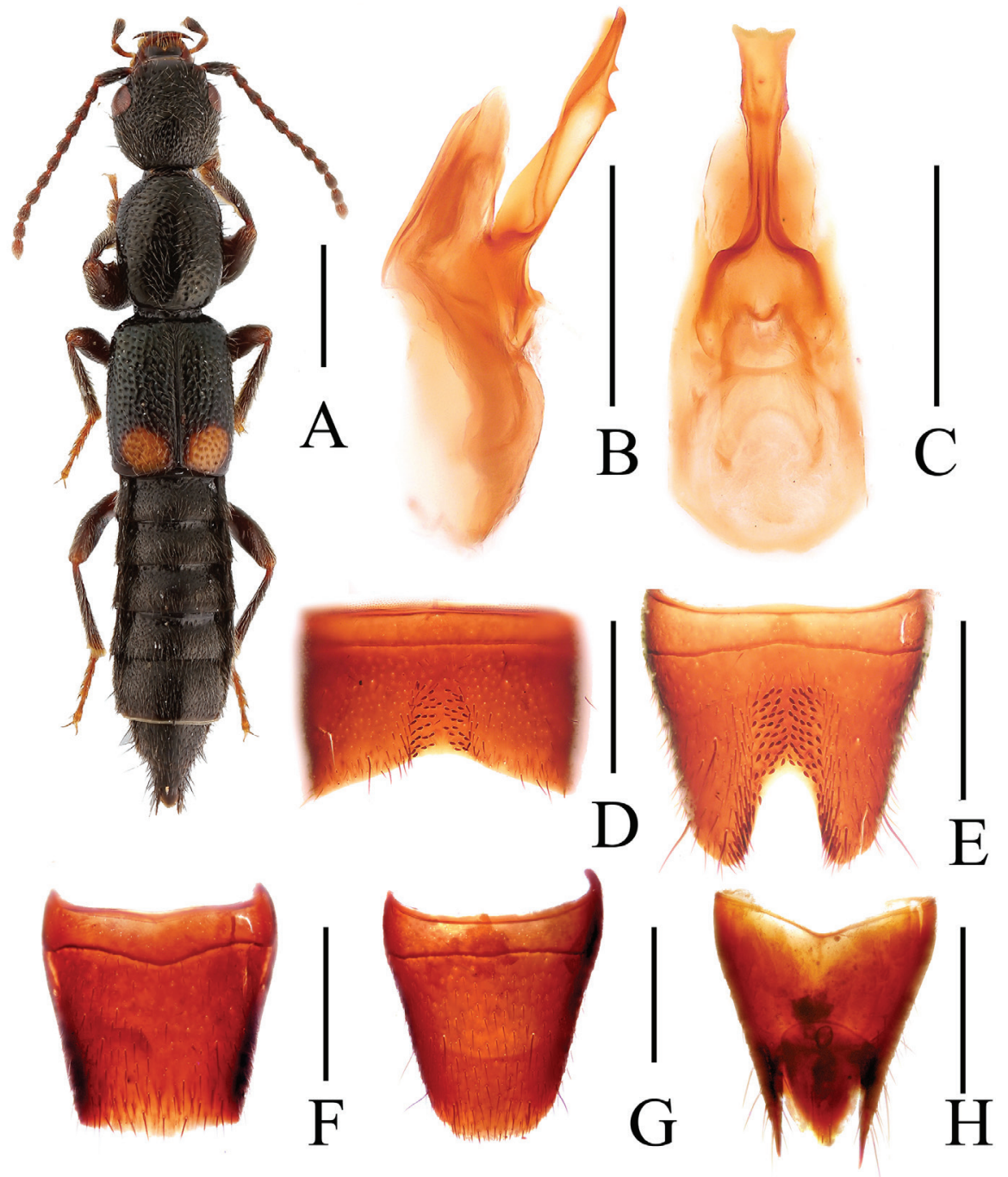

Figure 9. Lobrathium hebeatum. A habitus $\mathbf{B}$ aedeagus in lateral view $\mathbf{C}$ aedeagus in ventral view $\mathbf{D}$ male sternite VII E male sternite VIII F female tergite VIII G female sternite VIII $\mathbf{H}$ female tergites IX-X. Scales: A $1 \mathrm{~mm}, \mathbf{B}-\mathbf{H} 0.5 \mathrm{~mm}$.

\section{Lobrathium lirunyui $\mathrm{Li} \& \mathrm{Li}$, sp. n.}

urn:lsid:zoobank.org:act:BD413210-58A8-4AF0-88F7-F159C30D5E3E http://species-id.net/wiki/Lobrathium_lirunyui

Figs 11

Type material ( 1 đ̂). Holotype, $\widehat{\partial}$ : "China, Guizhou, Zunyi City, Fenghuang Shan, 800 m, $27^{\circ} 41^{\prime} \mathrm{N}, 106^{\circ} 55^{\prime} \mathrm{E}, 19-\mathrm{VI}-2012$, Li Run-yu leg. / Holotype ${ }^{1}$, Lobrathium lirunyui, sp. n. Li \& Li, det. 2013". 


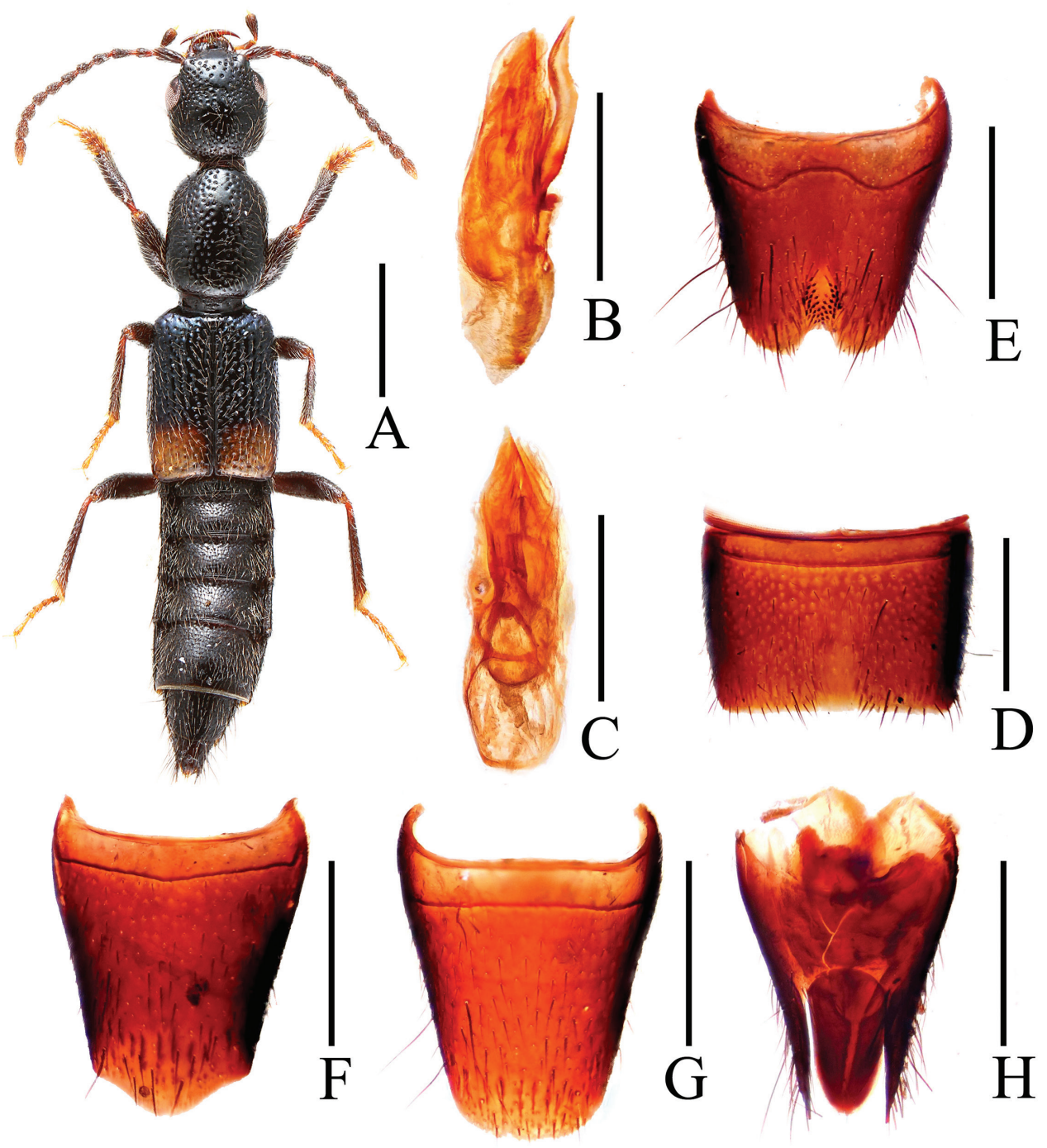

Figure 10. Lobrathium hongkongense. A habitus $\mathbf{B}$ aedeagus in lateral view $\mathbf{C}$ aedeagus in ventral view D male sternite VII E male sternite VIII F female tergite VIII G female sternite VIII $\mathbf{H}$ female tergites IX-X. Scales: A $1 \mathrm{~mm}, \mathbf{B}-\mathbf{H} 0.5 \mathrm{~mm}$.

Description. Large species, body length $9.40 \mathrm{~mm}$, length of fore body $4.20 \mathrm{~mm}$. Habitus as in Fig. 11A. Body reddish brown, legs reddish with pale-reddish tarsi, antennae reddish to brown.

Head longer than wide $(\mathrm{HL} / \mathrm{HW}=1.06)$, widest posteriorly; posterior angles weakly marked; punctation of dorsal surface fine and very dense; interstices without microsculpture. Eyes small, approximately one third the length of distance from posterior margin of eye to neck in dorsal view. Antenna long and slender, $2.50 \mathrm{~mm}$ long. 


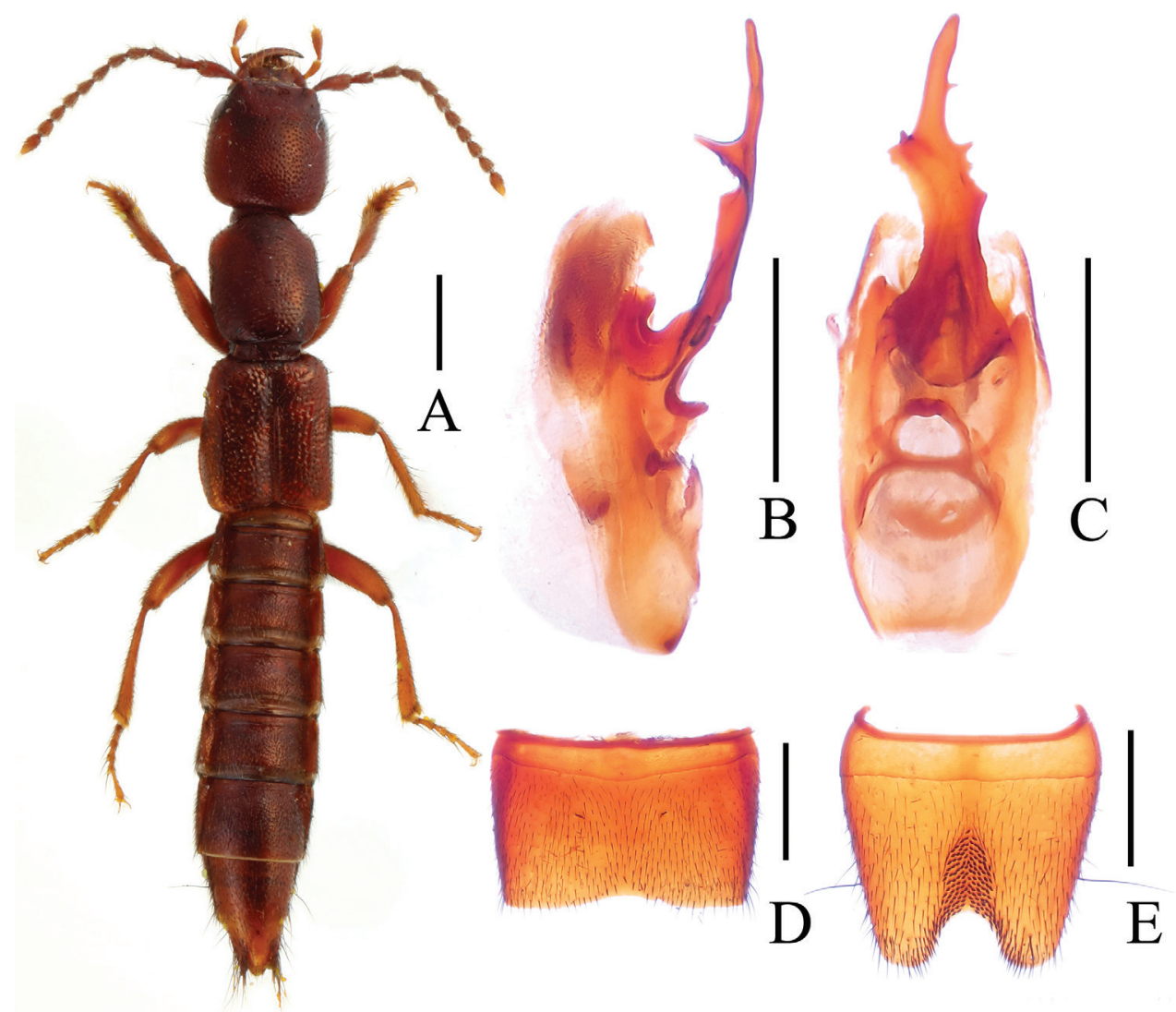

Figure I I. Lobrathium lirunyui. A habitus B aedeagus in lateral view $\mathbf{C}$ aedeagus in ventral view $\mathbf{D}$ male sternite VII E male sternite VIII. Scales: A $1 \mathrm{~mm}, \mathbf{B}-\mathbf{E} 0.5 \mathrm{~mm}$.

Pronotum slender $(\mathrm{PL} / \mathrm{PW}=1.28, \mathrm{PW} / \mathrm{HW}=0.90)$, lateral margins almost straight and subparallel in dorsal view; punctation similar to that of head, but with impunctate midline.

Elytra longer than wide $(\mathrm{EL} / \mathrm{EW}=1.02, \mathrm{EW} / \mathrm{PW}=1.25, \mathrm{EL} / \mathrm{PL}=1.08)$; punctation coarse and dense, arranged in somewhat irregular series; interstices without microsculpture. Hind wings apparently fully developed.

Abdomen distinctly narrower than elytra; punctation fine and dense; posterior margin of tergite VII with palisade fringe.

Male. Sternite VII (Fig. 11D) strongly transverse, and with shallow median impression posteriorly, without modified setae, posterior margin broadly and weakly concave; sternite VIII (Fig. 11E) weakly transverse, with long and extensive posteromedian impression, this impression with numerous modified, stout and short black setae, posterior excision rather broad and U-shaped, on either side of this excision with long dark submarginal setae; aedeagus (Figs 11B, C) $1.56 \mathrm{~mm}$ long, with asymmetric ventral process of distinctive shape. 
Female. Unknown

Etymology. The species is named after Runyu Li, collector of the holotype.

Comparative notes. This species is readily distinguished from all its congeners by the following character combination: elytra without spot, whole body of brownish coloration; punctation of head fine and dense, eyes very small, one third as long as distance from posterior margin of eye to neck, male sexual characters highly distinctive.

Habitat and distribution. The holotype was sifted in fern vegetation near a wet tree root (Fig. 20D) in the Fenghuang Shan, Guizhou (Fig. 19).

\section{Lobrathium pengi Li \& Li, sp. n.}

urn:Isid:zoobank.org:act:50DF2D82-E0AD-4B81-996D-BEFC980CD79A http://species-id.net/wiki/Lobrathium_pengi

Figs 12

Type material ( $7 \hat{\jmath} \widehat{\partial}, 3$ 우). Holotype, $\delta^{\lambda}$ : "China, Guangxi, Shangsi County, Shiwanda Shan, Forest Park, 300-500 m, 21 ${ }^{\circ} 54^{\prime}$ N, 10754'E, 25-IV-2011, Peng Zhong \& Zhu Jian-qing leg. / Holotype ${ }^{\lambda}$, Lobrathium pengi, sp. n. Li \& Li, det. 2013”. Paratypes, $6 \hat{\jmath} \hat{\gamma}^{\lambda}, 3+q$ : same data as holotype.

Description. Body length $6.34-7.34 \mathrm{~mm}$, length of fore body $3.11-3.73 \mathrm{~mm}$. Habitus as in Fig. 12A. Coloration: body black, elytra in posterior 1/3-2/5 with subcircular yellowish spot reaching posterior, but not lateral margins; legs yellowish with forelegs brown to blackish, femora and protibiae and tarsi paler; antennae brown.

Head weakly transverse $(\mathrm{HW} / \mathrm{HL}=1.02-1.03)$; posterior angles not marked; punctation coarse and dense, sparser in median dorsal portion, interstices without microsculpture. Eyes large, more than half as long as the distance from posterior margin of eye to neck. Antenna slender, $1.68-1.82 \mathrm{~mm}$ long.

Pronotum nearly as wide as head (PL/PW $=1.13-1.33$, PW/HW $=0.97-0.98)$, lateral margins weakly convex in dorsal view; punctation dense and coarse, similar to that of head, but with impunctate midline; interstices without microsculpture and glossy.

Elytra broader than pronotum $(\mathrm{EL} / \mathrm{EW}=1.0-1.06, \mathrm{EW} / \mathrm{PW}=1.35-1.40, \mathrm{EL} /$ $\mathrm{PL}=0.98-1.12$ ); humeral angles marked; punctation coarse and dense. Hind wings fully developed.

Abdomen distinctly narrower than elytra; punctation fine and dense; posterior margin of tergite VII with palisade fringe; tergite VIII (Fig. 12F) without appreciable sexual dimorphism, with weakly convex posterior margin.

Male. Sternite VII (Fig. 12D) strongly transverse, posterior impression of triangular shape and impunctate, posterior margin broadly and concave; sternite VIII (Fig. 12E) weakly transverse, without modified setae, posterior excision deep and rather narrow, on either side of this excision with long dark setae; aedeagus (Fig. $12 \mathrm{~B}, \mathrm{C}$ ) approximately $1.0 \mathrm{~mm}$ long, ventral process of very distinctive morphology, slender and furcate apically, bifurcation forming an angle of more than 30 degrees in lateral view. 


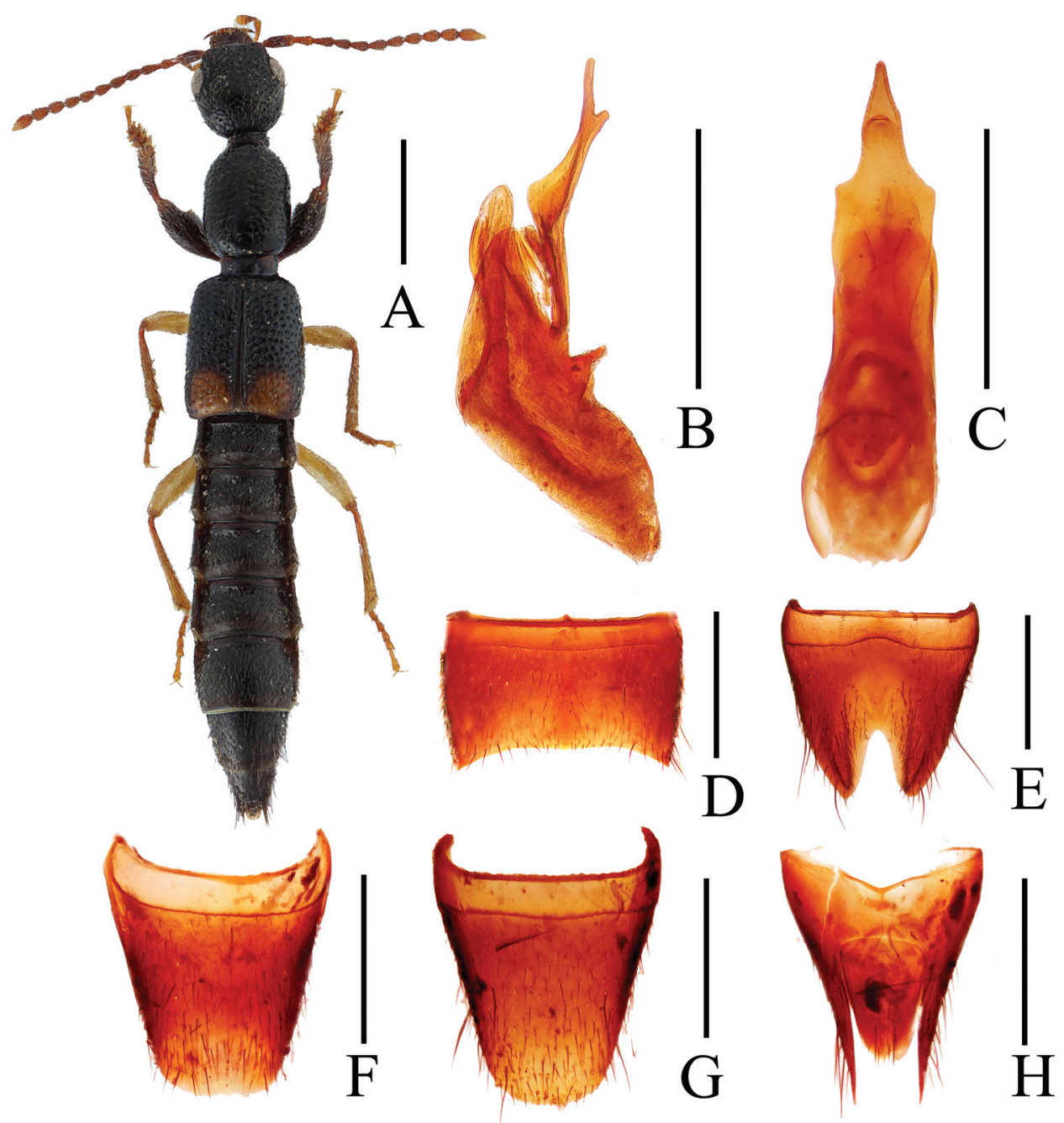

Figure 12. Lobrathium pengi. A habitus $\mathbf{B}$ aedeagus in lateral view $\mathbf{C}$ aedeagus in ventral view $\mathbf{D}$ male sternite VII $\mathbf{E}$ male sternite VIII $\mathbf{F}$ female tergite VIII $\mathbf{G}$ female sternite VIII $\mathbf{H}$ female tergites IX-X. Scales: A $1 \mathrm{~mm}, \mathbf{B}-\mathbf{H} 0.5 \mathrm{~mm}$.

Female. Sternite VIII as in Fig. 12G; tergites IX-X (Fig. 6H) relatively short; tergite IX undivided anteriorly, anterior martin emarginated in the middle; tergite $\mathrm{X}$ of subovoid shape.

Etymology. The species is named after Zhong Peng, collector of the type specimens.

Comparative notes. This species is similar to L. diaoluoense, from which it is separated by the broader and apically more abruptly narrowed ventral process of the 
aedeagus, with the apical bifurcation forming an angle of more than 30 degrees in lateral view.

Habitat and distribution. The specimens were sifted from wet moss along a streamside (Fig. 20E) in the Shiwanda Shan, Guangxi (Fig. 19), in April.

\section{Lobrathium quyuani Li \& Li, sp. n.}

urn:Isid:zoobank.org:act:B2CB6E5C-8ECB-453C-BB8C-1DA7F5969833

http://species-id.net/wiki/Lobrathium_quyuani

Figs 13

Material $(3 \precsim \precsim)$. Holotype, $ぇ$ : "China, Hubei, Wufeng County, Houhe National Reserve, $1100 \mathrm{~m}, 30^{\circ} 04^{\prime} \mathrm{N}, 110^{\circ} 37^{\prime} \mathrm{E}, 30-\mathrm{IV}-2004$, Li Li-zhen leg. / Holotype ${ }^{\top}$, Lo-

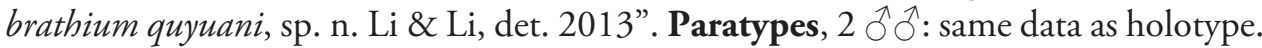

Description. Body length 5.78-6.34 mm, length of fore body $3.28-3.56 \mathrm{~mm}$. Habitus as in Fig. 13A. Coloration: body black with bluish hue, elytra with yellowish to reddish spot reaching posterior but not lateral margins; legs blackish with darkbrownish tarsi; antennae dark-brownish.

Head as wide as long $(\mathrm{HW} / \mathrm{HL}=0.96-1.03)$, widest at eyes; posterior angles broadly rounded; punctation dense and moderately coarse, sparser in median dorsal portion; interstices without microsculpture. Eyes large, more than half as long as the distance from posterior margin of eye to neck in dorsal view. Antenna slender, $1.72-1.95 \mathrm{~mm}$ long.

Pronotum slender $(\mathrm{PL} / \mathrm{PW}=1.25-1.41, \mathrm{PW} / \mathrm{HW}=0.92-1.0)$, lateral margins weakly convex in dorsal view, with impunctate midline, punctation similar to that of head, but distinctly sparser, interstices glossy.

Elytra longer than broad $(\mathrm{EL} / \mathrm{EW}=1.0-1.02, \mathrm{EW} / \mathrm{PW}=1.24-1.33, \mathrm{EL} / \mathrm{PL}=$ 1.0-1.05); punctation coarse and dense, arranged in irregular series; interstices without microsculpture. Hind wings fully developed.

Abdomen narrower than elytra; punctation fine and dense; posterior margin of tergite VII with palisade fringe; posterior margin of tergite VIII strongly convex in the middle.

Male. Sternite VII (Fig. 13D) strongly transverse, posteriorly with pronounced median impression, this impression of somewhat triangular shape, without punctation and pubescence, posterior margin broadly and very weakly concave; sternite VIII (Fig. 3E) weakly transverse, postero-median impression with modified, stout and short black setae, posterior excision deep and moderately broad, on either side of this excision with long dark submarginal setae; aedeagus (Figs 13B, C) $1.36 \mathrm{~mm}$ long, with weakly asymmetric and apically acute ventral process.

Female. Unknown

Etymology. The specific epithet refers to the famous late poet Yuan Qu, who was born in Yichang (Hubei), which is near the type locality. 

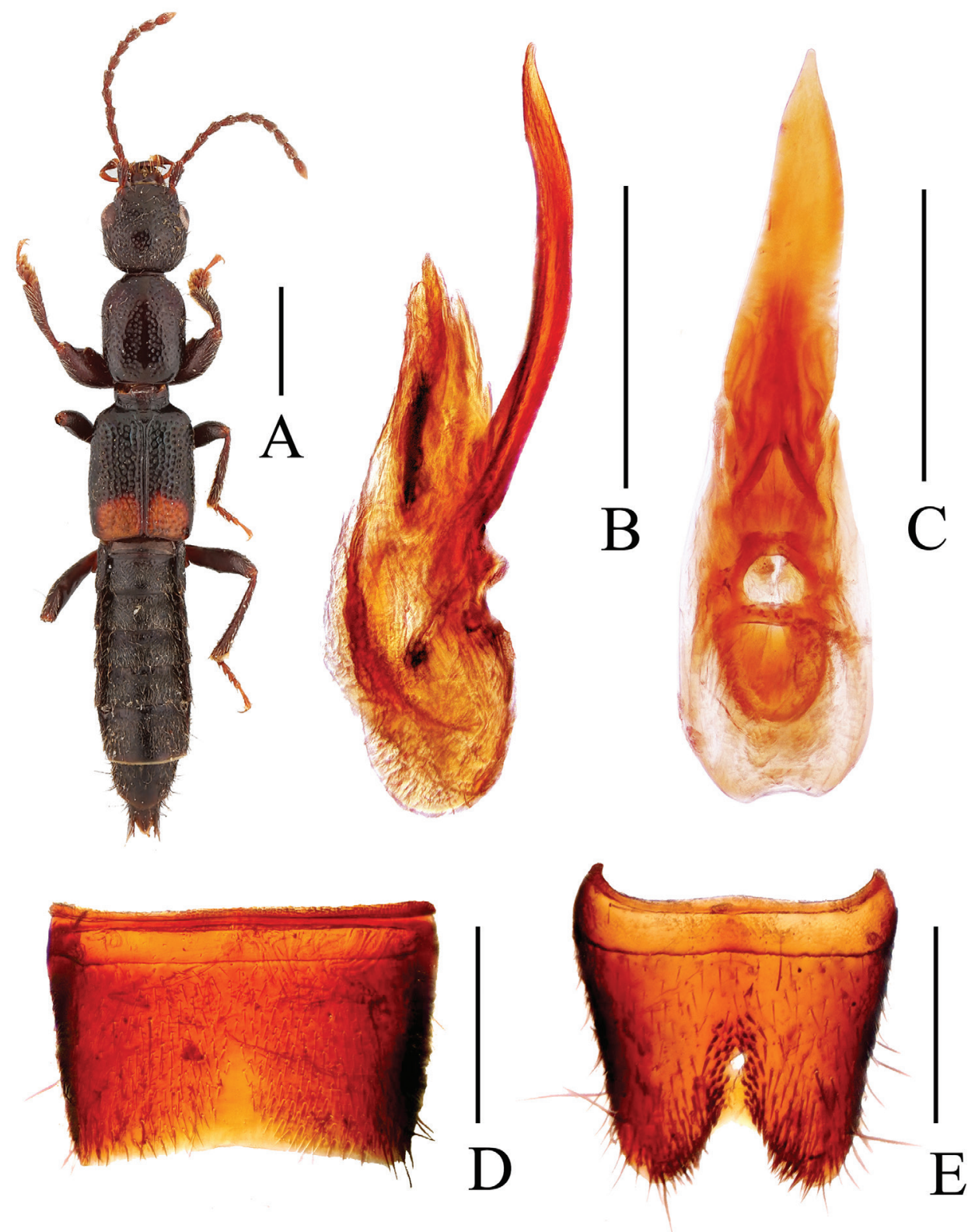

Figure 13. Lobrathium quyuani. A habitus $\mathbf{B}$ aedeagus in lateral view $\mathbf{C}$ aedeagus in ventral view $\mathbf{D}$ male sternite VII E male sternite VIII. Scales: A $1 \mathrm{~mm}$, B-E $0.5 \mathrm{~mm}$.

Comparative notes. This species is similar to L. configens Assing (2012) and $L$. spathulatum Assing (2012) in external characters. It is distinguished from both by the broader ventral process in ventral view.

Habitat and distribution. The specimens were sifted from wet moss near a stream (Fig. 20C) in the Houhe National Reserve, Hubei (Fig. 19). 


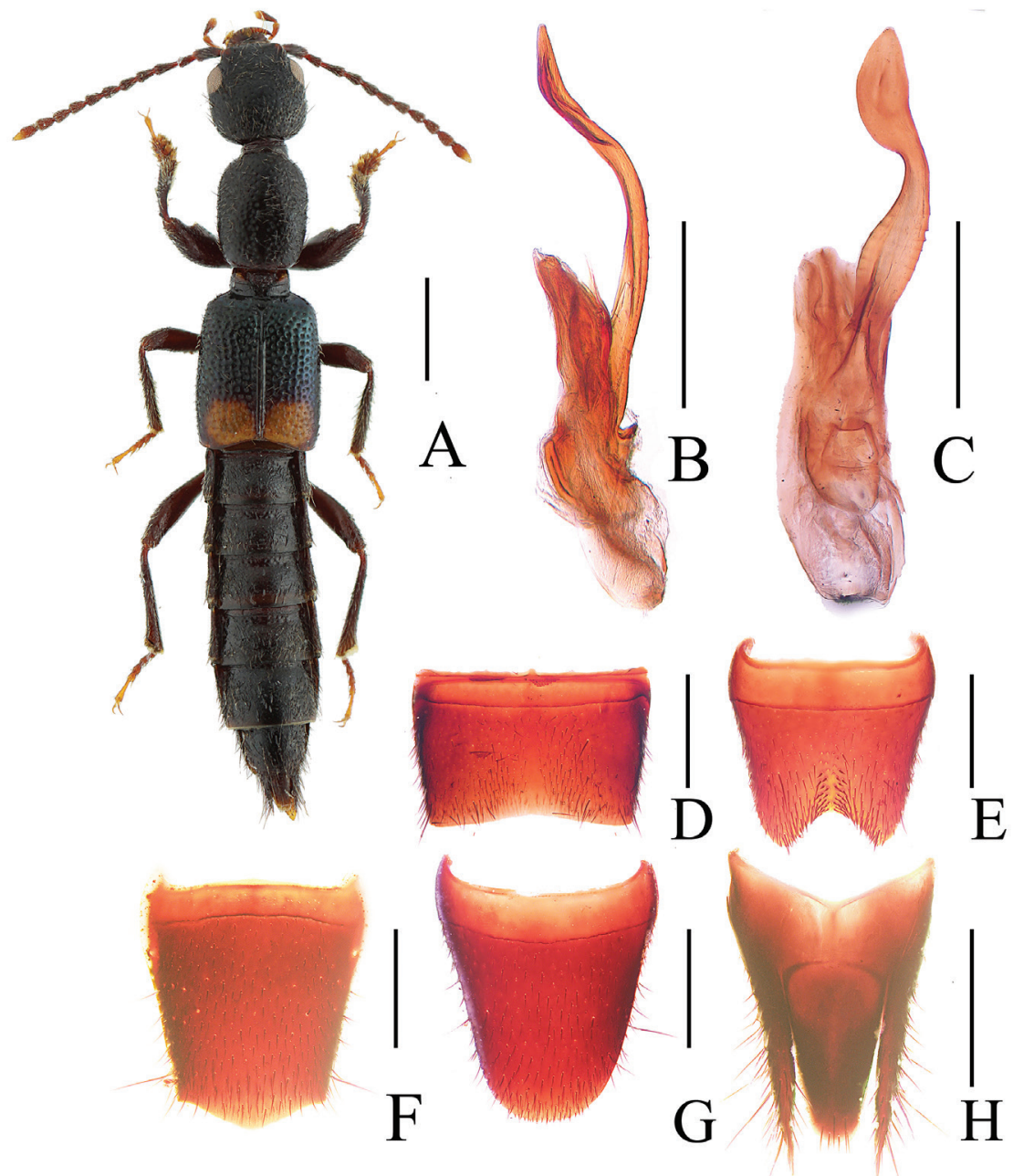

Figure 14. Lobrathium spathulatum. A habitus $\mathbf{B}$ aedeagus in lateral view $\mathbf{C}$ aedeagus in ventral view D male sternite VII E male sternite VIII $\mathbf{F}$ female tergite VIII $\mathbf{G}$ female sternite VIII $\mathbf{H}$ female tergites IX-X. Scales: A $1 \mathrm{~mm}, \mathbf{B}-\mathbf{H} 0.5 \mathrm{~mm}$.

\section{Lobrathium spathulatum Assing}

http://species-id.net/wiki/Lobrathium_spathulatum

Figs 14

Lobrathium spathulatum Assing, 2012: 95. Type locality: Pingwu, Sichuan.

Material examined ( $2 \hat{\jmath}, 2$ $+q)$. China, Zhejiang: $1 \hat{\jmath}, 1 \uparrow$, Anji County, Longwang Shan, Pingxi, 1000-1100 m, 09-VI-2012, Hu \& Yin leg.; 1 ふै, 1 ㅇ, Qingliangfeng, 1050-1070 m, 09-V-2005, Zhu \& Li leg.

Distribution. Widespread, recorded from Hubei, Shanxi, Zhejiang, Sichuan, and Shaanxi. 


\section{Lobratbium taureum Assing}

http://species-id.net/wiki/Lobrathium_taureum

Figs 15

Lobrathium taureum Assing, 2012: 100. Type locality: creek valley 8 km NW Muyuping, Daba Shan, Hubei.

Material examined $(1 \overbrace{}^{\lambda})$. China, Shanxi: $1 \partial^{\lambda}$, Ningwu County, Ximafang, $1430 \mathrm{~m}$, $38^{\circ} 39^{\prime} \mathrm{N}, 112^{\circ} 01^{\prime} \mathrm{E}, 04-\mathrm{IX}-2011$, Peng leg.

Distribution. Beijing, Hubei, Shanxi.

\section{Lobrathium tortile Zheng}

http://species-id.net/wiki/Lobrathium_tortile

Figs 16

Lobrathium tortile Zheng, 1988: 187. Type locality: Kangding, Sichuan.

Lobrathium tortile Zheng: Assing, 2012: 89. New distribution: Hubei, Sichuan, Shaanxi.

Additional material examined $(6 \hat{\partial}, 3 q \rho)$. China, Shaanxi: $1 \hat{\partial}$, Taibai Shan, $1450-1750 \mathrm{~m}, 34^{\circ} 03^{\prime} \mathrm{N}, 107^{\circ} 53^{\prime} \mathrm{E}-33^{\circ} 53^{\prime} \mathrm{N}, 107^{\circ} 48^{\prime} \mathrm{E}, 15-\mathrm{VII}-2004$, Hu \& Tang leg.; 3 $\widehat{\jmath}, 2$ 우, Zhouzhi County, Houzhenzi, Qinling Shan, West Sangongli Val-

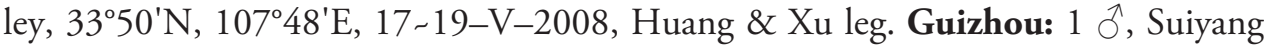
County, Kuankuoshui N. R., Baishaogou, 700 m, 28 $10^{\prime}$ N, 107 $16^{\prime}$ E, 03-VI-2010, $\mathrm{Lu}$ et al. leg. Sichuan: $1 \mathrm{\partial}^{\top}, 1$, Shimian County, Liziping, $1800 \mathrm{~m}, 28^{\circ} 59^{\prime} \mathrm{N}$, $102^{\circ} 28^{\prime} \mathrm{E}, 16-\mathrm{VII}-2012$, Dai et al. leg.

Distribution. Sichuan, Shaanxi, Hubei, Guizhou.

\section{Lobrathium tortuosum $\mathrm{Li}$ et al.}

http://species-id.net/wiki/Lobrathium_tortuosum

Figs 17

Lobrathium tortuosum Li, Solodovnikov \& Zhou, 2013: 574. Type locality: Fengyang Shan, Zhejiang.

Material examined $(3 \hat{\partial} \widehat{\partial}, 1$ ) $)$. China, Zhejiang: $1 \hat{\partial}$, Qingliangfeng, $1080 \mathrm{~m}, 08-\mathrm{V}-$ 2005, Zhu \& Li leg.; 1 ô, 1 + , Longquan City, Fengyang Shan, 1450-1600 m, 22-VII2006, Shen \& Li leg.; 1 गे, Baishanzu N.R., 1200-1360 m, 05-V-2004, Hu et al. leg.

Distribution. The original description of $L$. tortuosum is based on specimens from the Fengyang Shan, Zhejiang (Li et al., 2013). The above records from Qingliangfeng extend the distributional range about $200 \mathrm{~km}$ northwards. The known distribution is confined to the Tianmu Shan and the Donggong Shan in Zhejiang. 

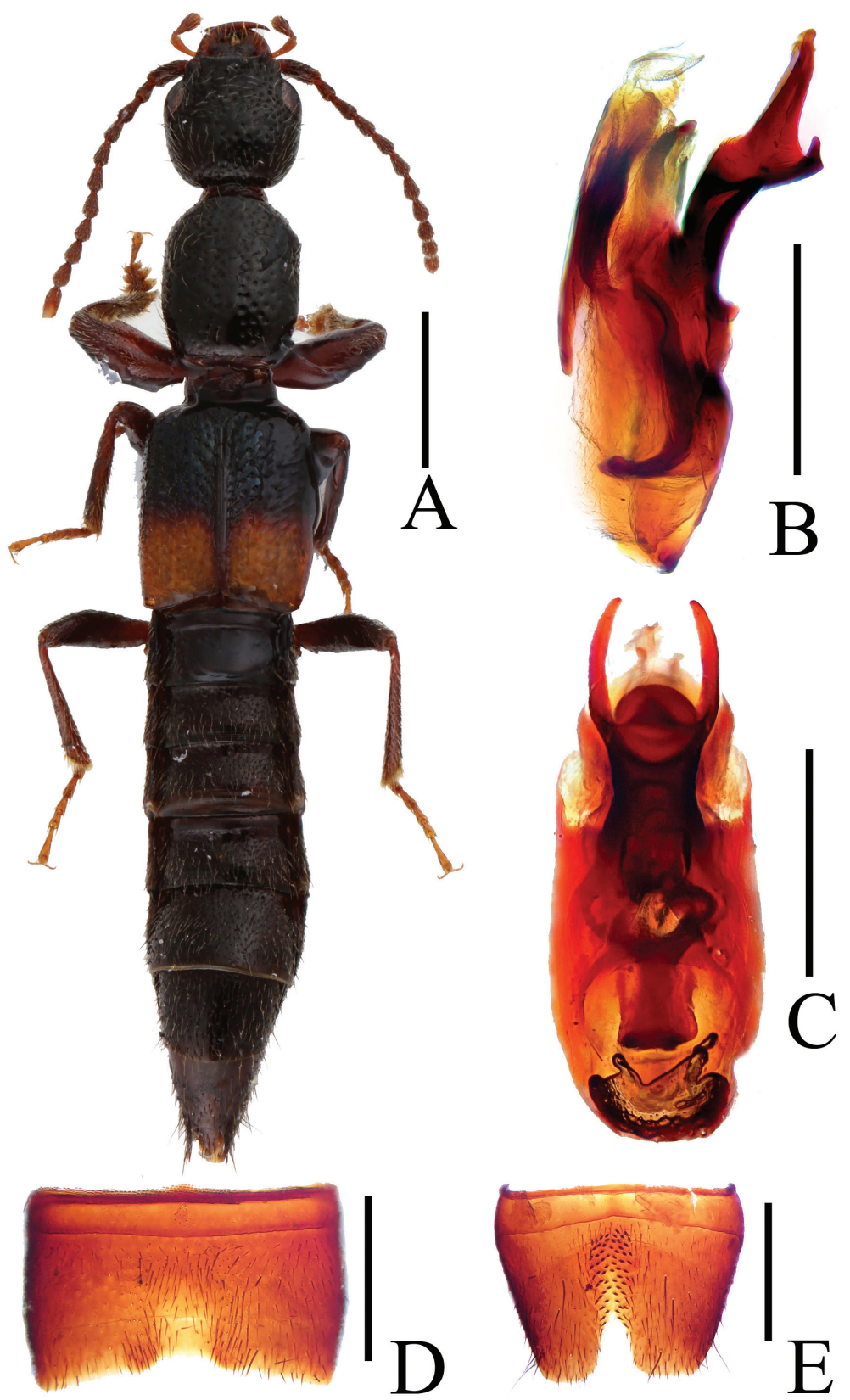

Figure 15. Lobrathium taureum. A habitus $\mathbf{B}$ aedeagus in lateral view $\mathbf{C}$ aedeagus in ventral view $\mathbf{D}$ male sternite VII E male sternite VIII. Scales: A $1 \mathrm{~mm}$, B-E $0.5 \mathrm{~mm}$. 


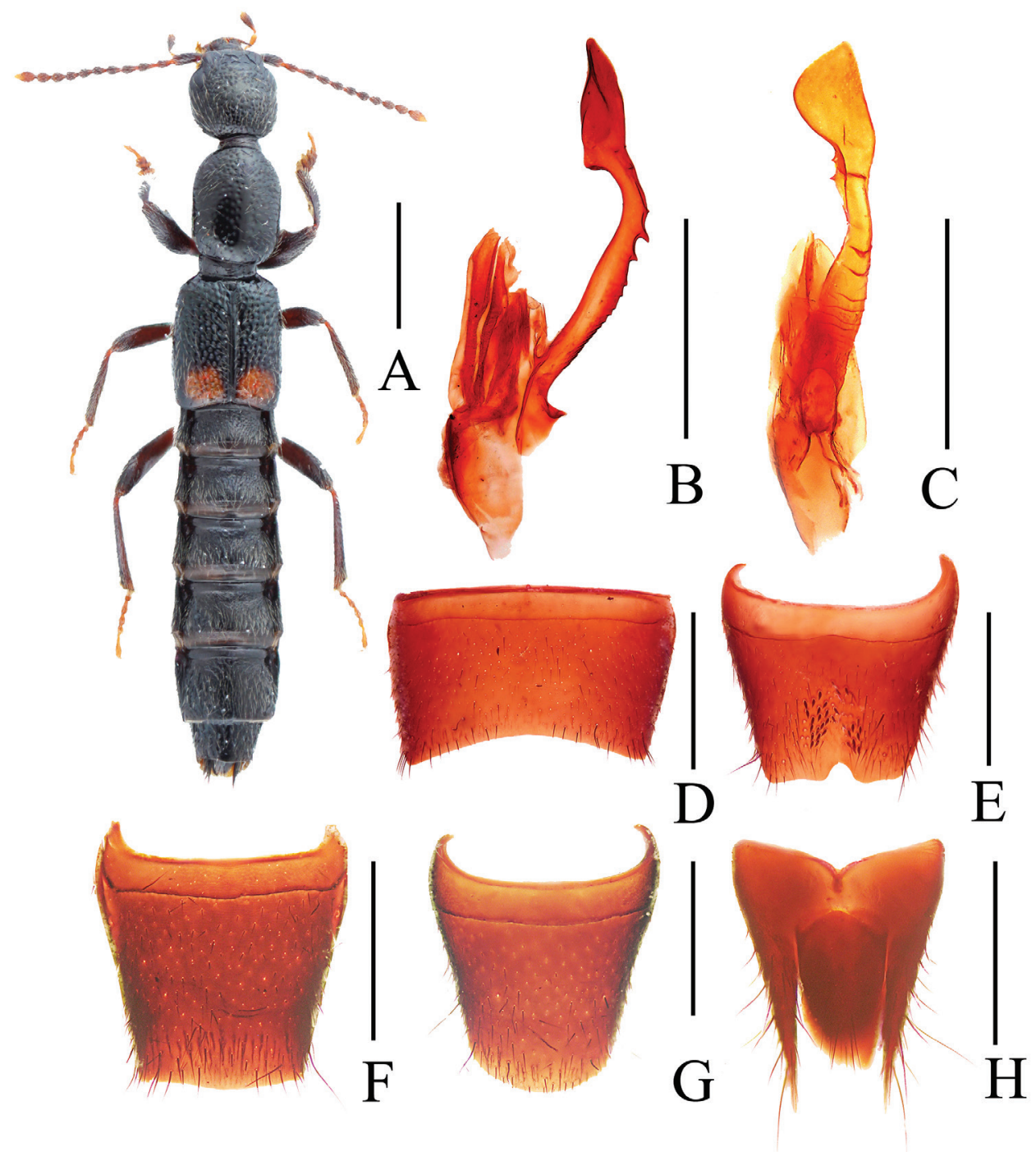

Figure 16. Lobrathium tortile. A habitus $\mathbf{B}$ aedeagus in lateral view $\mathbf{C}$ aedeagus in ventral view $\mathbf{D}$ male sternite VII E male sternite VIII F female tergite VIII G female sternite VIII $\mathbf{H}$ female tergites IX-X. Scales: A $1 \mathrm{~mm}, \mathbf{B}-\mathbf{H} 0.5 \mathrm{~mm}$.

\section{Lobrathium uncinatum $\mathrm{Li} \& \mathrm{Li}$ sp. n.}

urn:lsid:zoobank.org:act:A321CDF5-7B72-4699-BB65-C42C5C924BDF http://species-id.net/wiki/Lobrathium_uncinatum Figs 18A-F

Type material ( 1 đ̊). Holotype, đ̊: "China, Qinghai, Xining City, Huzhu County, Beishan National Reserve, 2450 m, 36 $56^{\prime} \mathrm{N}, 102^{\circ} 27^{\prime} \mathrm{E}, 28-\mathrm{VII}-2004$, Tang Liang, 


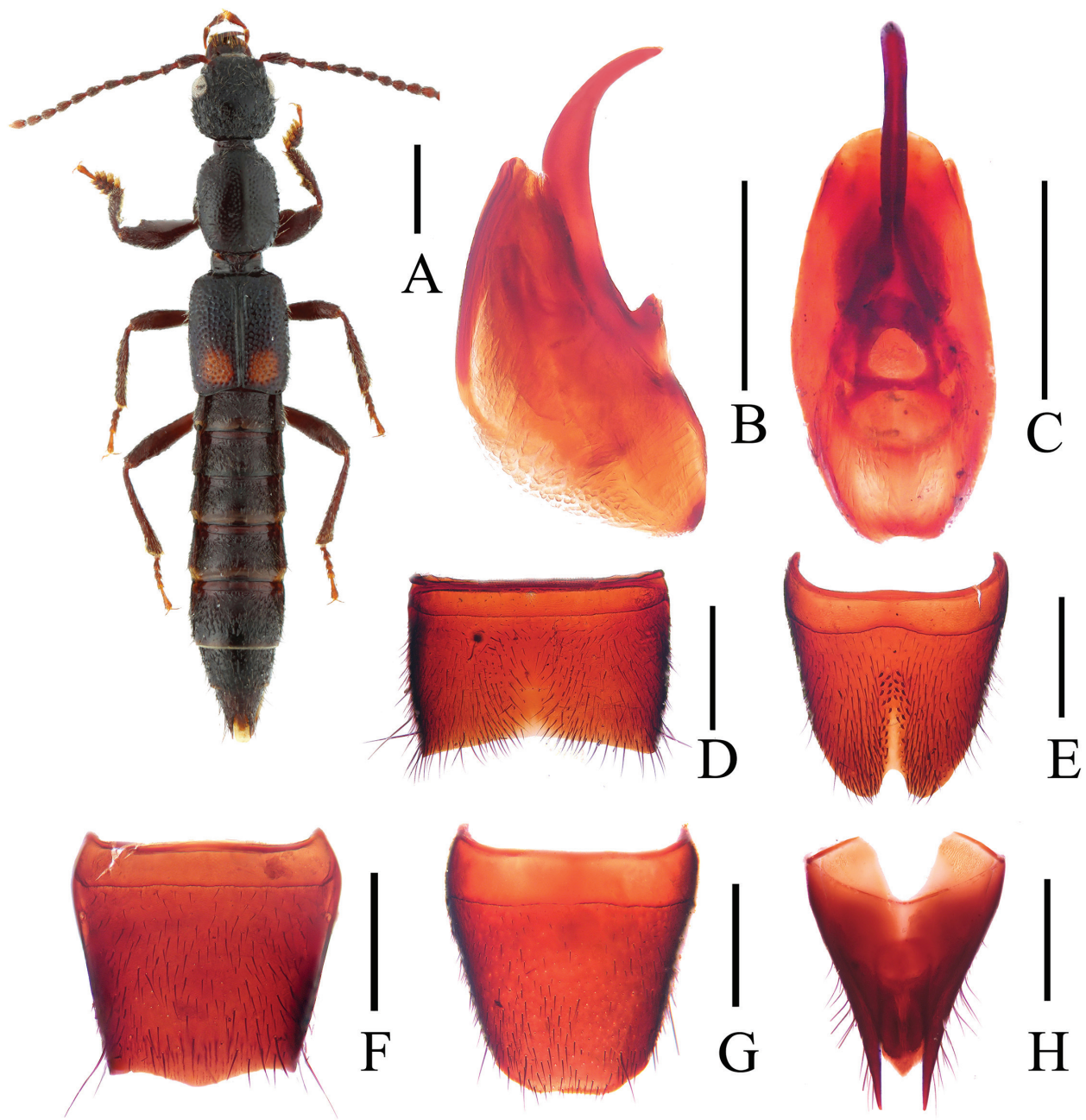

Figure 17. Lobrathium tortuosum. A habitus B aedeagus in lateral view $\mathbf{C}$ aedeagus in ventral view D male sternite VII E male sternite VIII F female tergite VIII G female sternite VIII $\mathbf{H}$ female tergites IX-X. Scales: A $1 \mathrm{~mm}, \mathbf{B}-\mathbf{H} 0.5 \mathrm{~mm}$.

Hu Jia-yao \& Zhu Li-long leg. / Holotype $\widehat{o}$, Lobrathium uncinatum, sp. n., Li \& Li, det. 2013".

Description. Body length $5.94 \mathrm{~mm}$, length of fore body $3.16 \mathrm{~mm}$. Habitus as in Fig. 18A. Coloration: body black, elytra posteriorly with large yellowish spot reaching posterior and lateral margins; legs reddish with paler tarsi; antennae reddish.

Head transverse $(\mathrm{HW} / \mathrm{HL}=1.14)$; posterior angles not marked; punctation coarse and dense, sparser in median dorsal portion, interstices without microsculpture. Eyes large, more than half as long as distance from posterior margin of eye to neck. Antenna slender, $1.92 \mathrm{~mm}$ long. 

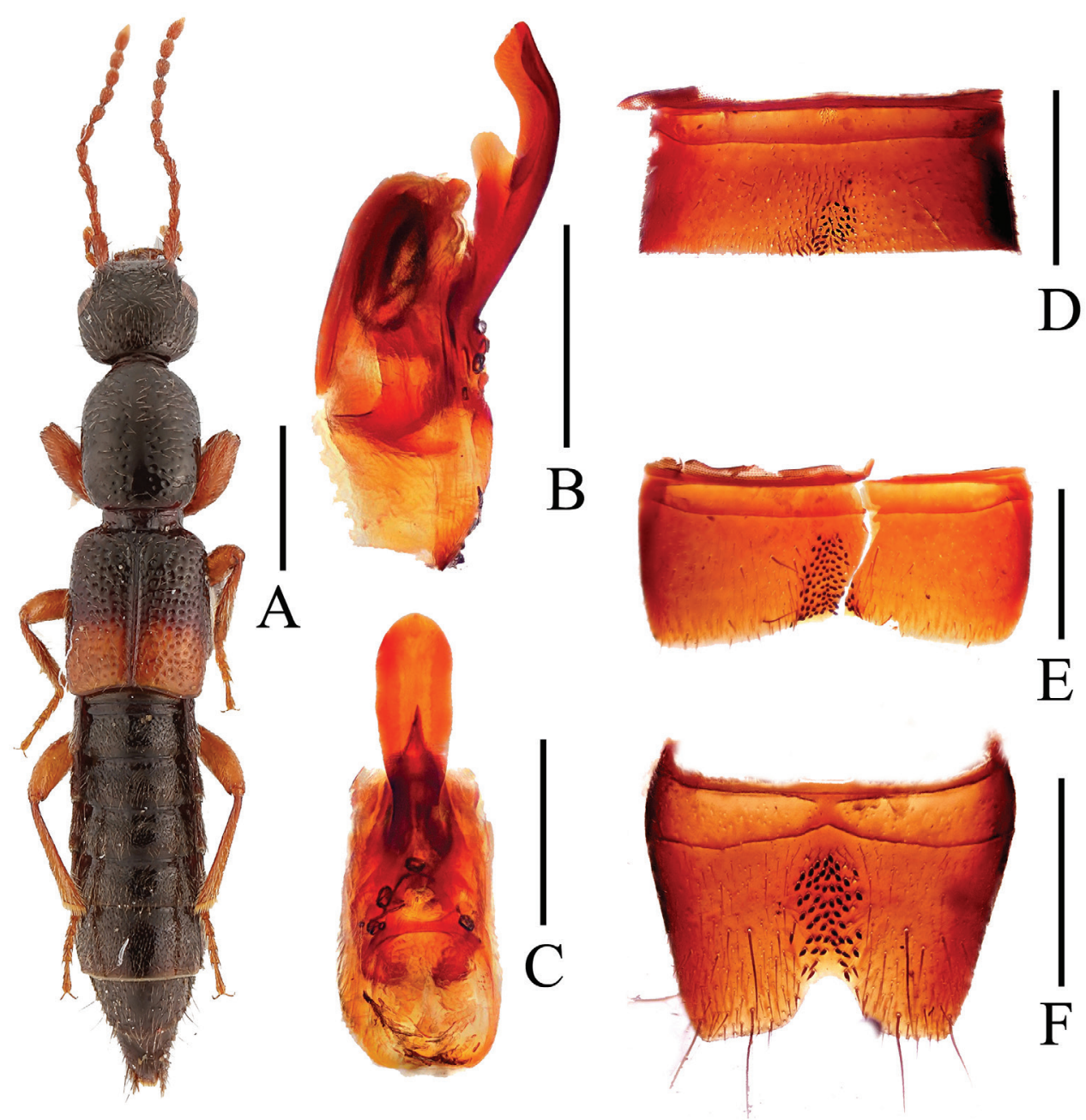

Figure 18. Lobrathium uncinatum. A habitus $\mathbf{B}$ aedeagus in lateral view $\mathbf{C}$ aedeagus in ventral view D male sternite VI E male tergite VII F male sternite VIII. Scales: A $1 \mathrm{~mm}, \mathbf{B}-\mathbf{F} 0.5 \mathrm{~mm}$.

Pronotum moderately oblong, as wide as head $(\mathrm{PL} / \mathrm{PW}=1.18, \mathrm{PW} / \mathrm{HW}=1.0)$; lateral margins subparallel in dorsal view; punctation dense and coarse, similar to that of head, but with impunctate midline; interstices without microsculpture and glossy.

Elytra longer than broad, broader than pronotum $(\mathrm{EL} / \mathrm{EW}=1.0, \mathrm{EW} / \mathrm{PW}=$ $1.29, \mathrm{EL} / \mathrm{PL}=0.98)$; humeral angles marked; punctation coarse and dense. Hind wings fully developed.

Abdomen narrower than elytra; punctation fine and dense; posterior margin of tergite VII with palisade fringe.

Male. Sternite VI (Fig. 18D) strongly transverse, postero-medially with modified stout black setae; sternite VII (Fig. 18E) strongly transverse, posteriorly with pro- 


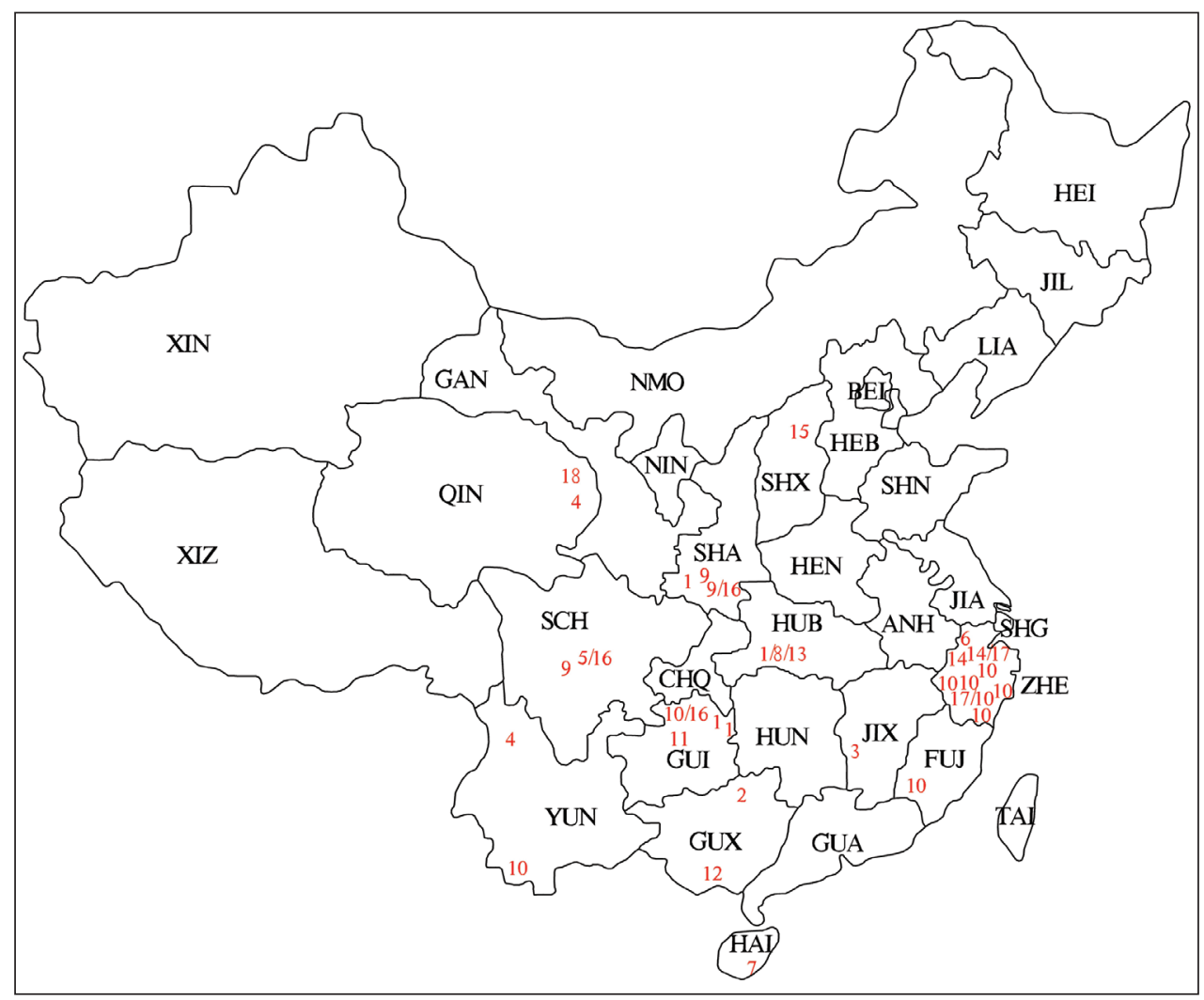

Figure 19. Map of collecting sites. I Lobrathium ablectum 2 L. anatitum 3 L. bispinosum 4 L. configens 5 L. daxuense 6 L. demptum 7 L. diaoluoense 8 L. dufui 9 L. hebeatum 10 L hongkongense I I L. lirunyui $\mathbf{1} \mathbf{2}$ L. pengi $\mathbf{1 3}$ L. quyuani $\mathbf{1 4}$ L. spathulatum $\mathbf{1 5}$ L. taureum $\mathbf{1 6}$ L. tortile $\mathbf{1 7}$ L. tortuosum $\mathbf{1 8}$ L. uncinatum. ANH Anhui; BEI Beijing; CHQ Chongqing; FUJ Fujian; GAN Gansu; GUA Guangdong; GUI Guizhou; GUX Guangxi; HAI Hainan; HEB Hebei; HEI Heilongjiang; HEN Henan; HUB Hubei; HUN Hunan; JIA Jiangsu; JIL Jilin; JIX Jiangxi; LIA Liaoning; NIN Ningxia; NMO Nei Mongol; QIN Qinghai; SCH Sichuan; SHA Shaanxi; SHG Shanghai; SHX Shanxi; SHN Shandong; TAI Taiwan; XIN Xinjiang; XIZ Xizang; YUN Yunnan; ZHE Zhejiang.

nounced impression, this impression with numerous modified stout black setae, posterior margin broadly and weakly concave; sternite VIII (Fig. 18F) transverse, posteromedian impression with modified setae like on sternites VI and VII, posteriorly with moderately deep excision; aedeagus (Figs 18B, C) with ventral process of distinctive morphology, near middle with distinct dorsal projection in lateral view.

Female. Unknown

Etymology. The specific epithet (Latin, hooked) refers to the shape of the ventral process of the aedeagus.

Comparative notes. This species can be separated from the externally similar $L$. taureum Assing (2012) and L. schuelkei Assing (2012) by the presence of modified se- 


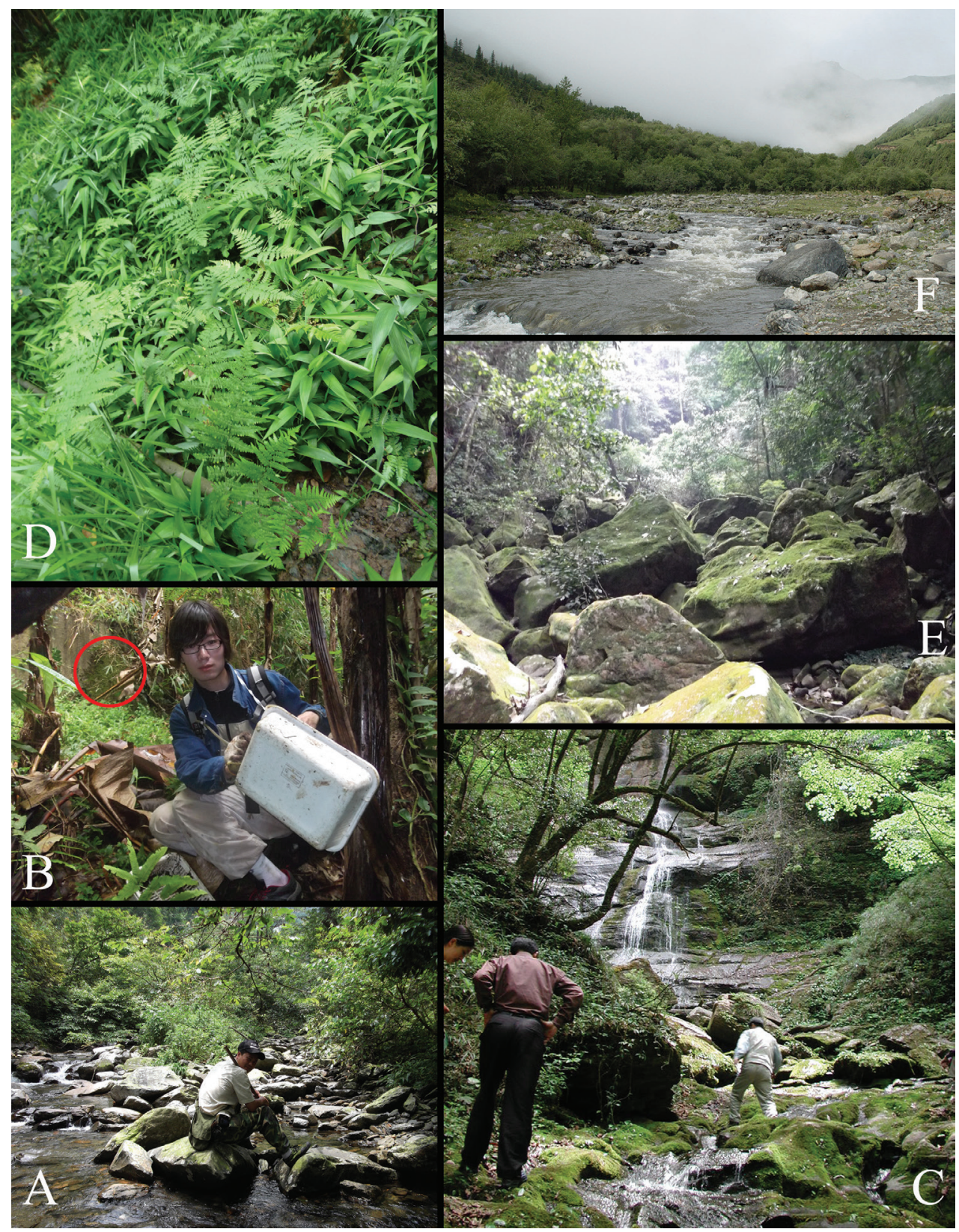

Firure 20. Habitat of new species. A Lobrathium anatitum B $L$. diaoluoense $\mathbf{C} L$. dufui; L. quyuani $\mathbf{D} L$. lirunyui $\mathbf{E}$ L. pengi $\mathbf{F}$ L. uncinatum.

tae on the male sternites VI and VII (Figs 18D, E) and by the distinctive shape of the ventral process of the aedeagus.

Habitat and distribution. The holotype was sifted from wet moss alongside a river bank (Fig. 20F) in the Meda National Reserve, Qinghai (Fig. 19). 


\section{Acknowledgements}

We thank Volker Assing (Hannover, Germany) for reviewing this manuscript. XiaoYan Li (Beijing, China) provided information on additional species for this study. The research was supported by the National Natural Science Foundation of China (No. 31101659) and Shanghai Normal University (DZL125).

\section{Reference}

Assing V (2010) On the Lathrobiina of Taiwan (Coleoptera: Staphylinidae: Paederinae). Beiträge zur Entomologie, Berlin 60:301-361.

Assing V (2012) A revision of East Palaearctic Lobrathium (Coleoptera: Staphylinidae: Paederinae). Bonn zoological Bulletin 61: 49-128.

Bernhauer M (1931) Zur Staphylinidenfauna des chinesischen Reiches. Wiener Entomologische Zeitung 48: 125-132.

Koch C (1939) Über neue und wenig bekannte paläarktische Paederinae (Coleoptera: Staphylinidae ) III. Entomologische Blätter 35: 156-172.

Li XY, Solodovnikov A, Zhou HZ (2013) Four new species of the genus Lobrathium Mulsant et Rey from China. Zootaxa 3635: 569-578. doi: 10.11646/zootaxa.3635.5.6

Smetana A (2004) Subfamily Paederinae Fleming, 1821. In: Löbl I \& Smetana A (eds): Catalogue of Palaearctic Coleoptera, Volume 2. Apollo Books, Stenstrup: 579-624.

Watanabe Y (1998) Two new apterous Lathrobium (Coleoptera, Staphylinidae) from the Tahsüeh Shan Mountains in Taiwan. Elytra 26: 303-311.

Zheng FK (1988) Five new species of the genus Lobrathium Mulsant et Rey from China (Coleoptera: Staphylinidae: Paederinae). Acta Entomologica Sinica 31: 186-193. 